University of New Hampshire

University of New Hampshire Scholars' Repository

$1-1-1986$

\title{
Information and Experience in Metaphor: A Perspective From Computer Analysis
}

Sylvia Weber Russell

University of New Hampshire, Durham, swr@cs.unh.edu

Follow this and additional works at: https://scholars.unh.edu/compsci_facpub

\section{Comments}

This is an Author's Original Manuscript of an article published by Taylor \& Francis in Metaphor and Symbolic Activity in 1986, available online: https://dx.doi.org/10.1207/s15327868ms0104_1

\section{Recommended Citation}

Sylvia Weber Russell - Information and Experience in Metaphor: A Perspective From Computer Analysis. Metaphor and Symbolic Activity 1 (4) (1986).

This Article is brought to you for free and open access by the Computer Science at University of New Hampshire Scholars' Repository. It has been accepted for inclusion in Computer Science Scholarship by an authorized administrator of University of New Hampshire Scholars' Repository. For more information, please contact Scholarly.Communication@unh.edu. 
Information and Experience in Metaphor:

A Perspective from Computer Analysis

Sylvia Weber Russell

Computer Science Department

University of New Hampshire

Durham, NH 03824

Published in

Metaphor and Symbolic Activity, Vol.1, No. 4 (1986)

Lawrence Erlbaum Associates, Inc. 


\begin{abstract}
Novel linguistic metaphor can be seen as the assignment of attributes to a topic through a vehicle belonging to another domain. The experience evoked by the vehicle is a significant aspect of the meaning of the metaphor, especially for abstract metaphor, which involves more than mere physical similarity. In this article I indicate, through description of a specific model, some possibilities as well as limitations of computer processing directed toward both informative and experiential/affective aspects of metaphor. A background to the discussion is given by other computational treatments of metaphor analysis, as well as by some questions about metaphor originating in other disciplines. The approach on which the present metaphor analysis model is based is consistent with a theory of language comprehension that includes both the intent of the originator and the effect on the recipient of the metaphor. The model addresses the dual problem of (a) determining potentially salient properties of the vehicle concept and (b) defining extensible symbolic representations of such properties, including affective and other connotations. The nature of the linguistic analysis underlying the model suggests how metaphoric expression of experiential components in abstract metaphor is dependent on the nominalization of actions and attributes. The inverse process of undoing such nominalizations in computer analysis of metaphor constitutes a translation of a metaphor to a "more literal" expression within the metaphornonmetaphor dichotomy.
\end{abstract}


Among metaphor researchers, the idea that anything specific could be claimed about the metaphoric process, especially on the basis of computerized metaphor analysis, is sometimes greeted with the comment that metaphor is inherently vague and not formalizable, that meaning cannot be equated with symbolic representations in any case, and that any attempt at computer interpretation is therefore destined to fail. Johnson (1982) argues that nonstructural or "preconceptual" elements of metaphor preclude any programmed simulation of the human ability to process metaphors. In the area of artificial intelligence, Winograd (1983) suggests that the computational paradigm is ill-suited to deal with the evocative aspects of language. Metaphor certainly has an evocative aspect, and this limit is acknowledged here. To date, however, little attempt has been made to sort out those aspects of metaphor that can be represented, to see what can in fact be done by computer analysis of both linguistic and extra-linguistic factors, whether for the purpose of information processing or for the sake of studying metaphor or linguistic communication itself.

The artificial intelligence approach to metaphor differs in motivation from approaches of researchers in some other disciplines; it is generally concerned with interpreting metaphor in the context of automated text or discourse comprehension, rather than with the nature of metaphor as a topic in itself. This article, however, assumes that the computational approach to natural language understanding--both metaphoric and nonmetaphoric--has a potential contribution to make regarding the understanding of expressive metaphor. That is, it assumes that efforts to specify elements of a computer model might reveal how metaphor comprehension is conceivably done--or not done.

The "validity" of a computer model along some specified dimension is suggested by its output, which in this case consists of literal paraphrases of the implicit meanings of input metaphors. A question of general interest is whether computer paraphrases reflect human understanding of metaphor, and whether they could approach human paraphrases of metaphor. The view assumed in this article does not go so far as to intend literally terms such as "computer understanding" and "computer interpretation." Rather, it is in contrast to both the view which regards the computational or artificial intelligence approach to language as an irrelevant piece of engineering, and the view which claims that computer programs will and should truly "understand" metaphor. A reasonable way of explicating the position presented here would be to consider a computational approach oriented toward depth of interpretation--an approach which takes both the informative and evocative aspects into account. It is this kind of approach on which the proposed model is based.

\section{THE QUESTION OF COMMUNICATED CONTENT}

Metaphor interpretations potentially produced by existing computational procedures might be adequate for determination of text coherence in the context of automatic processing. For metaphors which depart from mere physical similarity, however, the interpretations would not necessarily be "good" ones by human standards; human judges would recognize that there is often a difference between their own understanding and the concepts represented by the computer output. People could readily produce a string of adverbial descriptors and various phrases to give a more complete description of what was being said through such metaphors.

A challenge for a computer program would be to be able to produce such descriptors in a generalized fashion, but would even this be enough? An analysis of "He waltzed into a buzz saw of criticism" that produces a representation corresponding to "He unwittingly behaved in a way such that he was criticized" is adequately informative insofar as it indicates appropriate literal attributes and actions of the actors, but it does not present us with the speaker's attitudes--or evoke any chuckles. It appears that the more emotive or expressive (vs. explanatory) and the more creative or novel (vs. frozen) the metaphor, the more that seems to be missing from a computer output analysis.

In dealing with such observations, we might start at the point at which the concerns of the various disciplines would seem to overlap; namely, in the question, "What is communicated in a metaphor, and how?" This question involves several factors which, while not entirely neglected in the computer science literature, have not been focused on specifically to any great extent, such as the intent of the originator of the metaphor (i.e., what the originator wishes to accomplish), the role of affective factors, the relationship of metaphor to language in general, and the ways in which certain types of syntactic (as well as pragmatic) knowledge enter into 
comprehension of the metaphor. The analysis to be presented here rests on a view of meaning discussed more formally by MacKay (1969). That is, I am concerned not only with specification of logical properties of the metaphor itself, but also with the intent of the originator and the effect on the recipient of the metaphor. This approach serves the more general computational aim of analyzing metaphor in terms of human interests and goals.

An assumption critical to analysis along these lines concerns representation in terms of components or "primitives." Some of the available computer approaches depend on componential analysis of metaphoric expressions, while others tend to leave metaphoric terms intact, allowing richer interpretations but leaving some critical analysis problems unsolved. Since a metaphorically employed word is used in an extended sense, the information processing aspect of "understanding" metaphor depends partly on the extraction of inferences and other factors that are implicit in the metaphoric statement. Determining the nature of the extension necessitates componential analysis, at least in a broad sense. At the same time, this process breaks up the image on which the meaning of the metaphor relies. Thus, recourse to analysis in terms of components does not constitute an assumption that a metaphor is in reality perceived through components. The loss of cognitive content postulated by Black (1962) for human explication of metaphor applies with at least as much force to computer analysis.

The proposals presented in this article deal with certain aspects of comprehension in information-processing terms, but do not necessarily imply that metaphor or meaning is accounted for by the information-processing view or that the suggested representations exist in the mind as such. With an artificial intelligence perspective, we are concerned only with possibilities of automatically approximating a human's description or explanation of a metaphor through components. Although programs cannot capture, in terms of serial components, any image involved in metaphor understanding, they can extract factors that are invariant under metaphoric extension in terms of both components symbolizing the utterance and factors such as the goals of the originator. The program can then use these as a basis for coherence with respect to understanding the text or conversation in which the metaphor occurs. In an exploratory vein, the present discussion of such a program will confront the quixotic task of representing some of the vaguer aspects of metaphor.

I begin with some illustrations of how metaphorically expressed attitudes and experiences reflect the originator's intention toward the recipient. Then I (a) specify some computational tasks for a metaphor interpretation procedure which includes the extraction of experiential factors, (b) summarize other artificial intelligence work and the extent to which such tasks are addressed, (c) briefly give a theoretical framework for a previously implemented metaphor analysis program and an outline of its operation, (d) provide a basis for formalizing both informative and evocative aspects of verbal and nominal metaphor in terms of the relation between originator and recipient, (e) attend to the problem of determining salience for nominal metaphor and take into account reasons for salience, and finally (f) make some observations regarding limits of the described representations. The article concludes by showing how, from a linguistic point of view, metaphoric expression facilitates the originator's realization of purpose.

\section{EXPERIENTIAL METAPHOR AS A TOOL OF INTENTION}

In line with some current thinking in various disciplines, we can consider much of language as goaldirected behavior. In the field of artificial intelligence, Perrault and Allen (1980) and Allen and Perrault (1980) base their analysis of indirect speech acts on the view that the purpose of participants in a conversation is to have some effect on each other, whether this effect is an action or a new attitude. The assumption here is that if an interpretation of a linguistic expression is derived without regard to the intention of the originator, it cannot be said to represent the complete meaning of the expression.

Because metaphor is considered to be a particular mode of linguistic expression, we must ask whether there might be a particular purpose (other than brevity or alternate mode of expression) associated with use of the metaphor, and how this purpose might be related to the implicit content of the metaphor. Pollio, Barlow, Fine, and Pollio (1977) point to many purposes or intentions underlying the use of a metaphor. Of particular 
relevance to metaphor is intention in the sense of a (sometimes ulterior) motive. ${ }^{1}$ Such intentions may determine experiential components of a metaphor. Lakoff and Johnson (1980) have pointed out that literal language may not be able to convey such components. A consideration of this question is prerequisite to any theoretical conclusions about the capability of both computer programs and people to paraphrase metaphor. To investigate that aspect of metaphor which appears to elude computer representation as well as perhaps human paraphrases, it is useful to look at examples which are particularly evocative.

Consider the statement of AFL-CIO's Lane Kirkland that the Reagan Administration is practicing "Jonestown economics" with a budget that "administers economic Kool-Aid to the poor" (King, 1982). As with prosaic metaphorical usage in general, the assumption here is that one is vaguely familiar with the metaphoric vehicle (here, the Jonestown incident), and that one shares the prevalent attitude toward this vehicle. The speaker obviously wishes to exploit the listener's stored experience of shock associated with mass killings and apply it to a perception of the administration's budget. The speaker could have used a simple adjective such as "cruel," but chose this metaphor instead. Thus the listener not only is made aware of the speaker's assessment, but also experiences the shock associated with the Jonestown event and, momentarily at least, applies this rejection to the administration's budget. The metaphor has made use of both information and experience of negative emotions to persuade the listener. The listener may consequently either accept this image, fulfilling the speaker's intent, or may recoil from the comparison, if it seems too remote or even in poor taste.

Another example of persuasion through metaphor (actually a simile, but the point in this case is the same) appeals to humor (Dreikurs, 1964). A mother, trying to get her oblivious children to cease their rowdy behavior in the yard, is described as continually bursting though the front door "like a cuckoo clock" with the message that she has "just about had enough of you kids." Without the cuckoo clock image, the reader might still have understood that the mother was not making any progress in her attempts, and that the children were ignoring her. However, by evoking the perception--or rather unawareness--of a cuckoo clock to which one has become accustomed, the simile places the mother in an image (consistent with that held by the children) which merges her with the mechanical cuckoo. It is the humor of this--the simultaneous allusion to two disparate situations both seen as mildly negative--as much as any rational inferences from this image, which makes the reader see how ineffectual the mother's approach really is and thus evokes sympathy for the writer's point.

Literary description often entertains through metaphor by allowing fantasy. As Verbrugge (1980) points out, this is not to say that metaphor is merely an ornament. Viewed somewhat mechanistically, narrative prose sometimes invites the reader to "take a break from the information storage process" and enjoy the description. This in turn may motivate the reader to make a greater effort to visualize the topic or to identify with a character; alternatively, it may distract the reader. Consider the description of a house with passageways among which were to be found single steps "that seemed like spies from lost battalions, lying in wait and wondering where the rest had gone" (Garfield, cited in Townsend, 1974). The superimposition of "wondering spies" on what are ostensibly unremarkable steps retains the reader's attention as he or she shares an image originated by the writer.

These examples illustrate two possible intentions behind certain types of metaphor. One is persuasion, or sympathy for a particular point of view. Turbayne (1971) takes such "shifts in attitude through highlighting or filtering" as the mark of a good metaphor. A second intention is entertainment, which itself may serve another end. These intentions are fulfilled by appeals to the recipient's own attitudes toward familiar experiences, which have greater force to the extent the recipient has directly participated in such experiences. A metaphor vehicle points to and illuminates a concept or experience that an originator wishes to share, just as, analogously, specific examples in nonmetaphoric discourse may trigger one's own recreation or discovery of what the originator wishes to explain. The vehicles that are used guide the recipient's interpretations in line with the originator's intentions.

${ }^{1}$ This sense is not to be confused with the more general use of the term, as in the frequently made distinction between speaker's (intended) utterance meaning and sentence meaning (see Searle, 1979, for example). 
In all the preceding examples, information and intentionally evoked experience are simultaneously involved in the metaphor. However, whereas informational aspects of a novel metaphor could be communicated by paraphrases or sets of inferences or perhaps by other metaphors, the experiential aspect is particular to the vehicle image used, which may vary from one individual to another, but especially from one culture to another.

Computer programs, of course, can experience neither sympathy, entertainment, emotion, nor simultaneously perceived images. As automated recipients, they can analyze or break up the concept which serves as the vehicle, but not interpret or put back together an image with all its evocations. To the extent that an original metaphor is meant to motivate, symbolic representations of the metaphor are disappointing. However, considering the representation of both information and intentionally evoked experience in metaphor may point to better computer interpretations, which refer to if not realize what MacKay (1969) calls the "functional significance" of the communicated expression. The following section presents some computational requirements for interpreting a class of metaphor that includes experiential factors. It begins by relating possible computational approaches to some conventional theories of metaphor.

\section{COMPUTATIONAL TASKS}

Black (1972, 1979), following Richards (1936), developed an "interaction" theory (as opposed to a "substitution" or "comparison" theory) of metaphor. Without committing ourselves to any one theory as a whole, we can say that most computer implementations reflect limitations associated with the substitution theory. In particular, properties linked to the metaphorically used word (vehicle or source) are directly mapped to or substituted for the concept being expressed (topic or target), as if the transferred words were identical to rather than isomorphic to perceived properties of the topic of the metaphor, and could thus replace the metaphor. The interaction theory, by contrast, implies that the transferred properties become transformed through the metaphor, revealing something new. Furthermore, most artificial intelligence proposals, in keeping with the substitution theory, ignore connotations and valuations implicit in the transferred properties. A system design which accounted for the metaphoric extension (as opposed to literal transfer of ambiguous words) and included experiential components would be a step closer to realization of the interaction theory.

This orientation is not as critical for metaphor which is based mainly on physical similarities between target and source (e.g. the physical similarity between literal and metaphoric senses of "plow" in "The ship plowed the sea," and the common properties of the nominals in "The highway became a snake"). By contrast, in metaphors such as "He buried himself in forgetfulness" or "Dreams are gold mines, " either the target domain or source domain (or both) is not (merely) physical. These "concept-as-object" or "abstract" metaphors are avoided in most analyses of metaphor. They are important, however, in that they are based not merely on perceptual similarities or literally extended properties, but rather on underlying properties perceived as similar through some common (often experiential) component. Abstract metaphor is therefore particularly relevant to any discussion of experiential factors implicit in metaphor, and its representation will receive most of our attention here.

In the process of implementing such a system of metaphor comprehension, one question to be addressed concerns how the parts of a metaphor are represented, which in turn determines whether and how extended inferences can be computationally extracted from the metaphor. Because our particular concern here is to show how salient factors are extended and extracted, representations must be based on some kind of analysis, such as semantic decomposition, that allows us to retrieve or describe such factors.

A second requirement of a model of metaphor comprehension is a means of determining what is represented, that is, what is salient to the interpretation. The choice among various possibilities involves reference to different kinds of context of the metaphoric expression. The disambiguation of metaphor in discursive context, with its identifiable dependence on intention, can be seen as analogous to computational analysis strategies in which "planning" plays an important role. A plan is a sequence of projected actions designed to achieve a goal; it provides explanatory links between a state or event and a goal. Schank and Abelson (1977) illustrate how plans can be used to analyze paragraphs that omit information presumably used by recipients to 
understand the text. Generation of responses to indirect speech acts or sentence fragments through a planning system is a focus of the work of Perrault, Allen and Cohen (1978; see also Allen \& Perrault, 1980; Perrault \& Allen, 1980). If a metaphor serves the intentions and goals of the originator, it can be seen as fitting into a plan concerning the person to whom the metaphor is addressed. In an analysis of at least some metaphors, therefore, the choice of alternative salient characteristics can conceivably be disambiguated if the goal of the originator is known. Conversely, a goal of an originator of an experiential metaphor, or a plan element, can be surmised through calculation of a likely effect of a metaphor. This article examines particular aspects of metaphor in line with the latter possibility. However, this discussion minimizes reference to extrasentential discursive context in favor of considering what can be extracted from various kinds of knowledge about terms within the metaphor itself.

Of primary interest in this discussion, then, are (a) representations that isolate extensible inferences and intended experiential factors such as affects and (b) guides to salience determination that give insights into the nature and purpose of metaphor. These factors have been both addressed and ignored to varying degrees in artificial intelligence work on the processing of metaphor.

\section{ARTIFICIAL INTELLIGENCE RESEARCH ON METAPHOR}

All the approaches presented here deal at least implicitly with metaphoric inferences in a broad sense. In addition, most refer to structure-mapping mechanisms for transferring information from variously formatted "frames," or organized representations of knowledge, for metaphorically used concepts. The approaches, however, vary in their ability to represent metaphoric extension, especially of connotations.

The work of Gentner $(1975,1980,1982)$, though in the area of psychology, is related to the concerns expressed here. In her experiments on verb recall, Gentner has found support for the theory that verbs are stored as interrelated sets of components, which suggests that component properties and relations (rather than verbal concepts as a whole) are extended in metaphor. Gentner views the ground of a metaphor (i.e., the shared aspects of topic and vehicle) in terms of identifiable predicates that express attributions or relations. She has presented experimental evidence that it is relations which are principally extended (and therefore salient) in metaphorical and analogical comparisons. Thus for the statement "The atom is analogous to the solar system," the objects in both the atomic and solar systems participate in similar relations: sun/nucleus ATTRACTS planet/electron, planet/electron ATTRACTS sun/nucleus, sun/nucleus MORE MASSIVE THAN planet/electron, planet/electron REVOLVES AROUND sun/nucleus. By contrast, the attributes of the sun--YELLOW, HOT, MASSIVE (absolute sense)--are not extended to the nucleus of the atom.

Gentner thus describes the broad types of properties likely to be extended, within the basic attribute/relation dichotomy. The kind of representation system she assumes (i.e., of verbal decomposition, as in the propositional networks of Norman \& Rumelhart, 1975) is suited to representing these and further distinguished properties. With respect to affective metaphor, as found in expressive metaphor such as poetry, Gentner points out difficulties in specifying clear structure mappings. She maintains that in expressive analogy the emphasis is on the number and density of the relationships rather than on their clarity and consistency; she also maintains that surface sensory attributes play a greater role in expressive metaphors, which are thus less "abstract." In her experiments, however, subject data in fact showed a positive correlation between clarity and expressiveness. Furthermore, Gentner has made an interesting observation with respect to a Shakespearean literary metaphor ("Juliet is the sun"), which is relatively clear. In the contextual metaphoric passage of this sentence, the primary subject being conveyed is relationships (viz., Juliet causes hope and gladness in Romeo, just as the sun does). The incorporation of such affective relationships into structural representations is a feature of the proposed computational system.

Wilks (1977b, 1978) shares the approach of Gentner insofar as attention to the nature of metaphoric extension at the level of language representation is important to his research on computerized metaphor comprehension. He uses a "primitive" case-based structure as a "formula" to represent a metaphorically used verb (case representations are based on the view that the underlying structure of a simple sentence is that of a verb surrounded by one or more noun phrases, each of which fills a "role" or "case" associated with the verb). Thus 
he represents the verb "drink" as a CAUSING to MOVE, preferably done by an ANIMATE SUBJECT (= agent) to a liquid (OBJECT), TO a particular ANIMATE aperture (THRU PART) and INTO the SELF (= the animate agent). The analytic output determined by this structure complements information derived from knowledge structures stored with definitions of contextual nominals. For example, for "car," Wilks gives the partial knowledge structure of Figure 1.

For "My car drinks gasoline," "drink" in the input indirectly matches "inject" in the knowledge structure: both are CAUSE (to) MOVE verbs with the case-based inference that the object (liquid, gasoline) is IN the car. Furthermore, to determine what cars literally do with gasoline, the procedure seeks the structure in the knowledge representation which is the closest match to the input source structure. This would be "IC (Internal Combustion) Engine (USE) \#liquid," because \#liquid matches the object in the source structure ("gasoline") and IC Engine is a part of a car and may substitute for it. Thus USE can be projected onto "drink, " giving "My car uses gasoline." Wilks's system, then, heuristically arrives at an interpretation by actively using world knowledge to alter verb sense representations as required by contextual nominals.

For physical-domain metaphors in which there is a strong semantic link between the nominal concepts, the incorporation of projection into metaphor analyses provides interpretations which are more reliable and more specific than interpretations derived from mere extraction of information from the vehicle. On the other hand, it is unclear how such mechanisms would be applied to more creative metaphor or to abstract metaphor, where corresponding literal interpretations are not as obvious and are not necessarily suggested by a knowledge structure of the subject nominal. For instance, there does not appear to be a unique knowledge structure for "country," since that concept is not unambiguously thought of as having well-defined functions. Aside from the question of projection, the capability to extend structures and inferences is present in Wilks's system, but there is no focus on affective and other underlying salient factors.
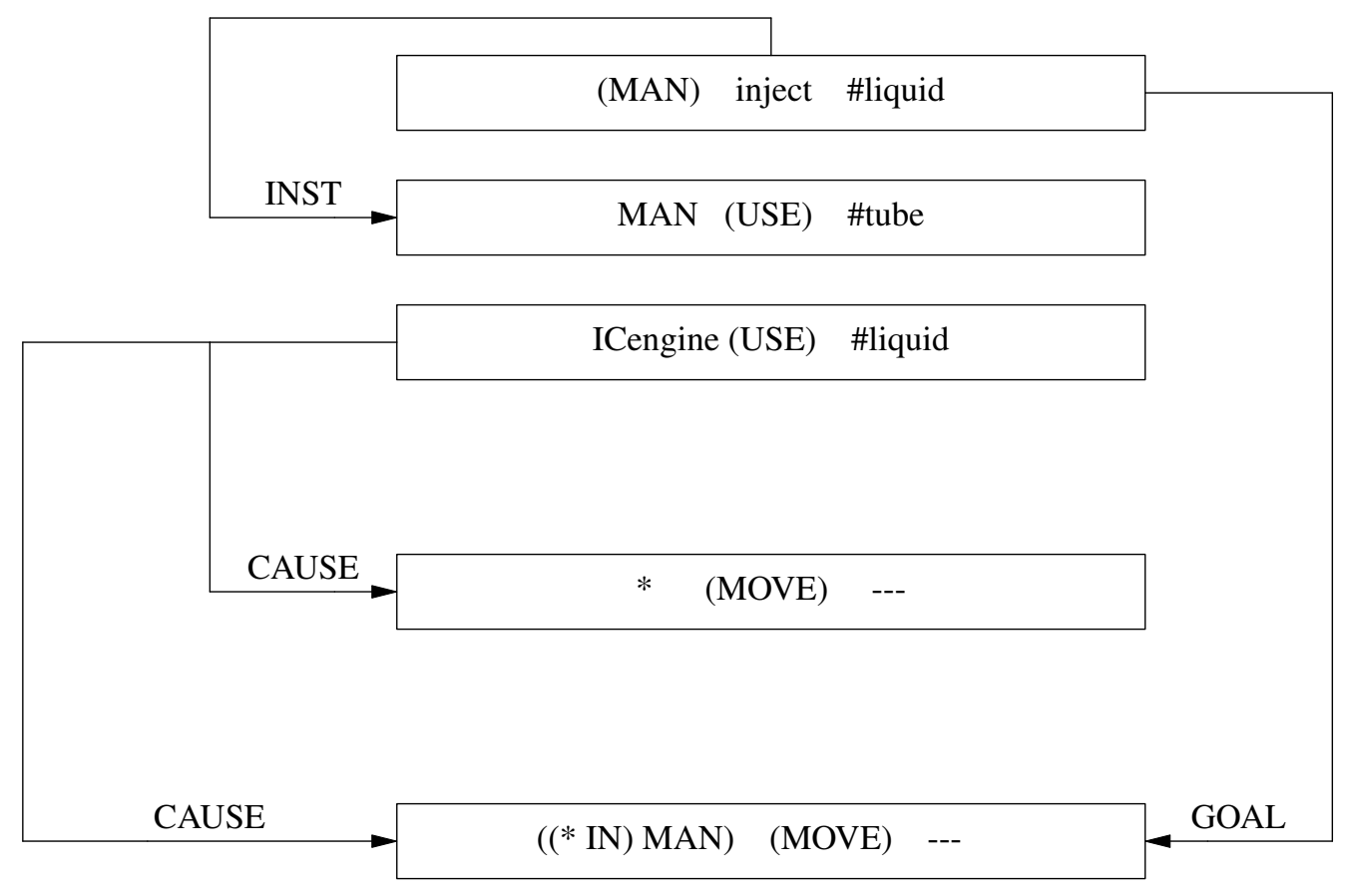

Figure 1. Wilks' (partial) pseudo-text for the nominal "car" (INSTRUMENT and CAUSE arrows show the relationships between various properties of the knowledge representation; '\#' indicates a thesaurus subheading, i.e. nonprimitive low-level category; uppercase words represent primitives; asterisks indicate equivalence to a class of primitives). Note. From "Making Preferences More Active" by Y. Wilks, 1978, Artificial Intelligence, 11, p. 208. Copyright 1978 by North-Holland Publishing Company. Reprinted by permission. 
In more recent research in this area, Fass and Wilks (1983) incorporate this method with other strategies to recognize metaphor. This further development is motivated in part by the observation that the strategy previously described, when confronted with "The car drank gasoline and purred to itself," could find no interpretation for "purred to itself." To represent the metaphorical ambiguity (is "car" seen as animate or is "drink" the car-like consuming of gasoline?), Fass and Wilks draw on two other strategies. For the first clause, "The car drank gasoline," a "change-the-expectation" strategy changes the expected SUBJECT of "drink" from ANIMATE to VEHICLE. A competing "change-the-data" strategy changes the subject nominal "car" from VEHICLE to ANIMATE. The missing subject nominal for "purred to itself" is derived from the representation indicating the latter strategy, because the unaltered subject nominal (VEHICLE) in the former representation leads to a "preference violation" (the preferred subject of "purred" is ANIMATE). This gives the representation "(car (ANIMATE)) --> (purred (SUBJ ANIMATE))." This kind of analysis is directed toward the recognition of ambiguity as opposed to interpretation. The output does not reflect a concern with literal topic components, such as the nature of the noise made by the car (engine).

Indurkhya's (1985) treatment of phrasal (mainly verbal) metaphor is concerned with the feasibility of implementing the structure-mapping mechanism and with the algorithmic and computational properties of such a mechanism. The object of his study is the precise specification of structural coherence of mappings (consistency of structural constraints in source and target domains). Because Indurkhya relies on the matching process (which he sees as the determination of structural analogy) for selection of elements transferred to the target domain, his focus is on physical-domain metaphors, in which literal similarity is apparent. He also gives some attention, however, to "weakly coherent" metaphors, in which there is no evident literal similarity. In this area, his assignment of unmatched information to the target from the source domain is similar to the procedure discussed later in this article.

In Indurkhya's system, domain knowledge is represented as lists of statements in predicate calculus. In his approach, he considers, for example, "The sky is crying," preprocessed as "cry (sky)." Here "cry" is in the EMOTIONAL-STATE domain and "sky" is in the WEATHER domain. These domain representations are therefore retrieved, as shown in Table 1.

Table 1

Examples of Indurkhya's Domain Representations

DOMAIN 5: EMOTIONAL-STATE

1. cry(eyes) -> fall-down (tear-drops, eyes)

2. cry(eyes) <-> cry(person) AND part-of (person, eyes)

3. cry(person) -> very-happy(person) $\Theta$ very-sad(person)

4. laugh(person) -> very-happy(person)

5. very-happy(person) $->$ NOT very-sad(person)

6. [ blue (eyes) $\Theta$ dark (eyes) $\Theta$ brown (eyes) ]

AND NOT [ blue (eyes) AND dark (eyes) AND brown (eyes) ]

7. liquid (tear-drops)

8. heavy (tear-drops)

DOMAIN 6: WEATHER

1. blue (sky) <-> sunny(sky)

2. blue (sky) <-> day AND clear (sky)

3. sunny(sky) <-> day AND clear (sky)

4. gray (sky) <-> day AND cloudy (sky)

5. starry(sky) -> night AND clear (sky) 
6. contains (sky, full-moon) -> night AND clear (sky)

7. contains (sky, full-moon) -> NOT starry(sky)

8. raining(sky) $\rightarrow>$ cloudy(sky)

9. raining(sky) -> [ gray (sky) AND day] OR [ dark (sky) AND night ]

10. raining(sky) <-> fall-down (rain-drops, sky)

11. snowing(sky) -> cloudy(sky)

12. snowing(sky) -> [ gray (sky) AND day] OR [ dark (sky) AND night]

13. snowing(sky) <-> fall-down (snow-flakes, sky)

14. heavy (rain-drops)

15. liquid (rain-drops)

16. light (snow-flakes)

17. solid (snow-flakes)

Note. The construct "X $\Theta$ Y" means "(X OR Y) AND NOT (X AND Y)", i.e. "X or Y but not both". From "A Computational Theory of Metaphor Comprehension and Analogical Reasoning" (Tech. Rep. No. 85/001, pp. 162-163) by B. Indurkhya, 1985, Boston: Boston University. Copyright 1985 by B. Indurkhya. Reprinted by permission.

The procedure first looks at constraints of EMOTIONAL-STATE in which "cry" appears. At some point, Constraint 1 matches both Constraints 10 and 13 of WEATHER. Constraint 13 suggests the mapping "(cry -> snowing); (eyes -> sky); (tear-drops -> snow-flakes)." In verifying the coherence of this mapping, it is found that Constraints 7 and 8 are contradicted by Constraints 17 and 16 of WEATHER, respectively, so they are not transferable. If the context demands another interpretation, Constraint 10 of WEATHER is chosen, in which case Constraint 1, 7, and 8 are transferable, leading to the interpretation "raining (sky)." A further procedure, which posits the existence of a token in WEATHER corresponding to "person" of EMOTIONAL-STATE, allows transfer of human attributes such as "sadness." Thus, although Indurkhya does not refer to how connotations and experience work in comprehension of metaphor, he does allow for the transfer of affects in the form of inferential statements which appear in the domain frame of the vehicle.

With regard to the goal of extensibility, Indurkhya does not have a system of primitives to facilitate the extraction of implicit information. However, the predicate calculus statements that make up his domain knowledge frames are somewhat redundant and may include paraphrases in terms of lower level verbs (such as "move-through"). Such lower level verbs serve a function equivalent to that of primitives in an interpretation of "The ship plowed through the sea" in terms of "sailing." Thus in contrast to most of the researchers to follow, Indurkhya does not ignore the problem of extension by relying exclusively on transfer of high-level identical predicates.

On the other hand, a working model of metaphor comprehension would require further semantic analysis to ensure intelligible target interpretations. For instance, the specification of "sky" as an actor of "rain" seems forced. Both in his method and in that of Wilks (who also looks at the metaphoric topic in his "projection" process), there is a domain-assignment problem for nominals which potentially belong to many specific domains. That is, it would seem that the classification of "sky" must remain more general (e.g., PHYSICAL) or ambiguous until we know that we are talking about rain or weather. Wilks, however, through his case-based inferences and semantic relationships within his frames, is able to confirm his "guess" for the example he gives. Lacking this facility, Indurkhya's system would have difficulty finding a match for "My car drinks gasoline."

With an orientation somewhat different from that of the preceding researchers, Hobbs $(1979,1981)$ maintains that the mechanisms for selecting relevant inferences from metaphor and for formalizing the context which determines such selection are those which a natural language understanding system uses to process nonmetaphorical language. In his system, metaphoric extension is represented by axioms formulated in terms of predicate calculus. Thus the general metaphor which expresses a variable as an entity at a location is formalized as "variable $(x) \&$ value $(w, y, x)-->$ at $(w, x, y)$ "; if $w$ is the condition of $y$ being the value of the variable $x$, then $w$ is also the condition of $x$ being at $y$. 
To represent complex novel metaphors, Hobbs proposes "schemata," which he defines as collections of axioms interrelated by the co-occurrence of some of the same predicates. To illustrate, he uses the example, "We insist on serving up these veto pitches that come over the plate the size of a pumpkin," from a Democratic congressman complaining about President Ford's vetoes (Salmans, DeFrank, Buresh, \& Hubbard, 1975). Situations are encoded, for example, as "send (SD,C,B,P)," where SD is the action by Congress $\mathrm{C}$ of sending the bill B to the President $\mathrm{P}$, and "pitch $(p, x, y, z)$," in which $p$ is the pitching $p$ by the pitcher $x$ of the ball $y$ to the batter $z$. The metaphor is then represented as two schemata linked as in Figure 2.

To uncover the analogy, Hobbs tries to match predicates describing the metaphorical terms with those derived from world knowledge about the topic (cf. Wilks's "projection" from a knowledge structure). Thus "sending a ball to a pitcher" (from baseball knowledge) is matched with "sending a bill to the President" (from knowledge about vetoes).

This example indicates how natural language understanding program mechanisms and concept matching in particular can play a role in computerized metaphor comprehension. In denying that metaphors are "recognized" as such or are processed differently from literal language, however, Hobbs ignores systematic semantic analysis of the metaphorically extended concepts themselves. (Is "send" a unique representation component, or were overlapping senses fortuitously matched?) Also, with its high-level focus on situations, this approach does not address the extraction of evocative and other factors underlying metaphorically used words.

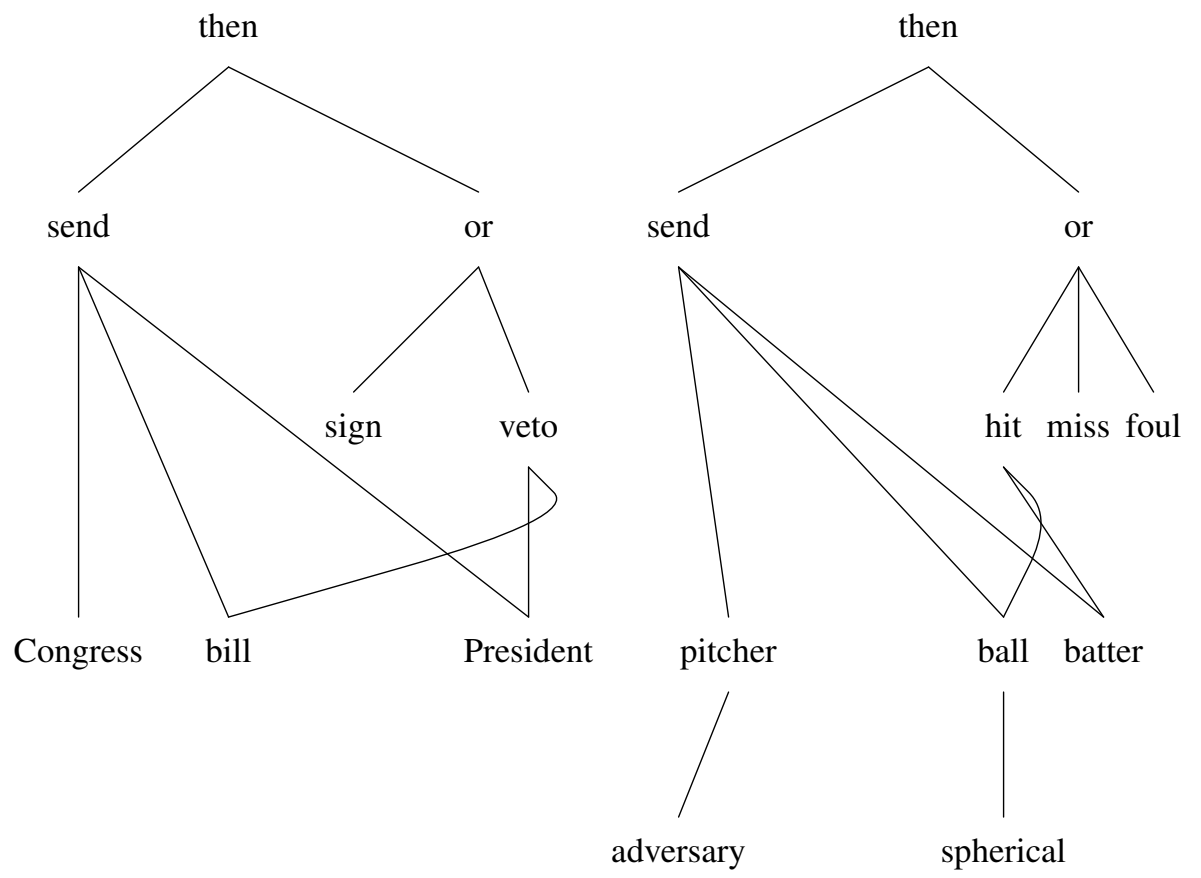

Figure 2. An example of Hobbs's representation of metaphor as linked schemata.

Carbonell $(1980,1982)$ pursues in greater depth several aspects of computerized comprehension of metaphor in context. He maintains that a purpose of metaphor is to structure inferences, including goals and plans of the actors in the target domain. Some problems of metaphor analysis are circumvented in Carbonell's model through "recognition" of prestored conventional metaphor formulas--those identified by Lakoff and Johnson (1980), such as "MORE IS UP" and "IDEAS ARE FOOD." In other words, the initial strategy of Carbonell's system consists of a top-down rather than a reconstructive bottom-up method. For example, to interpret the New York Times headline, "Speculators brace for a crash in the soaring gold market," Carbonell's system matches "soaring" ("upward movement") with "up" and matches "increase in value or volume" of "gold 
market" with "more" in the "MORE IS UP" metaphor formula. Propositions attached to "soaring" can be transferred to "gold market": "The increase is rapid and not firmly supported; if it tumbles it may undergo a negative state change." Here there is a mapping from physical to financial states that is carried through the analysis of the other part of the sentence: "Speculators brace [prepare] for a [physical/financial negative state change caused by a physical/financial] crash."

Carbonell demonstrates that metaphors are sometimes used to structure entire conversations. For instance, the goal of "defeating" or "curing inflation" follows from "INFLATION IS WAR" and "INFLATION IS A DISEASE" metaphors, respectively. The process of determining transferred inferences is aided by reference to transferable salient properties or categories assembled in an invariance hierarchy. This heuristic hierarchy explicitly ranks potentially salient factors (as observed through study of about 200 examples). Carbonell's hierarchy, in decreasing order of expected invariance, is:

(1) A goal-expectation setting for the animate actors involved (if any), as in the "INFLATION IS WAR" example.

(2) Planning and counterplanning strategies among competing or cooperating actors.

(3) Causal structures.

(4) Functional attributes.

(5) Temporal orderings.

(6) Natural tendencies (water tends to go downhill; therefore electricity tends to go towards the voltage drop).

(7) Social roles (in the "INFLATION IS A DISEASE" metaphor, wage-earners are patients).

(8) Structural relations (see Gentner).

(9) Descriptive properties (less likely to be preserved in metaphor).

(10) Object identity (almost never mapped: there are no tanks in the "battle against inflation").

In more recent work, Carbonell and Minton (1983) specify their analogy-based mechanisms in terms of transfer of portions of a graph consisting of concepts (nodes) linked by relations. Thus for "X is a puppet of $Y$," the node CONTROL between the object "puppet" and the actor "puppeteer" is transferred to the node between " $X$ " and " $Y$." The absence of an appropriate pre-existing mapping for the source domain initiates the comparison of source and target domains to create new mappings, a process constrained by the invariance hierarchy.

Carbonell and Minton thus have both a heuristic means of determining that a property is salient and specific representations to support the analogy recognition they see as underlying metaphor analysis. As in the case of Hobbs, however, their research on metaphorical reasoning and analogies is mainly at the level of situations. They do not deal with either the metaphoric nature or affective features of transferred properties themselves. For example, analogical inferences such as "firmly supported" do not appear to be further analyzed (disambiguated) in Carbonell's and Minton's system.

Kilpatrick (1982) directly addresses the determination of transferred salient properties of the vehicle in nominal metaphor. In his view, metaphor comprehension is "the ability to use shared stereotypic values to understand the metaphorical utterance" (p. 84). His approach is therefore to store stereotypical and prototypical properties directly with the vehicle concept, as opposed to searching for possibly salient properties in a knowledge representation of the concept. He defines vehicle frames in terms of "stereotypic bundles" as well as nonstereotypic properties. Thus, for the example "The hearings are a blunderbuss," the stereotypic bundle for "blunderbuss" is retrieved from its frame definition, given in Table 2.

Kilpatrick's focus on stereotypic and prototypic properties can be seen as an implicit recognition of subjectivity in metaphor. As with Hobbs and Carbonell, however, Kilpatrick has not dealt with affective factors or further analyzed the stereotypic properties themselves. That is, his representations do not show how "kill" is metaphoric with respect to the effect on the object. He says only that "kill" is somehow tempered in its 
application to the hearings.

Table 2

Kilpatrick's (1982) Frame for the Nominal "Blunderbuss."

\begin{tabular}{|lll|}
\hline blunderbuss & & \\
& A kind of: & $\begin{array}{l}\text { weapon } \\
\text { rifle }\end{array}$ \\
Stereotype & Function: & kill object of aim \\
bundle & Accuracy: & -7 \\
& Shot pattern: & random \\
& & scattered \\
& & \\
Prototype & Actors & \\
values & agent: & shooter \\
& object: & game \\
& & enemy \\
& Physical description & \\
& muzzle shape: & bell \\
& length: & -5 \\
& & \\
\hline
\end{tabular}

Note. From "An A-Frame Model for Metaphor" by P. W. Kilpatrick, 1982, Proceedings of the International Conference on Cybernetics and Society (p. 85). Copyright 1982 by IEEE. Reprinted by permission.

Weiner (1984), in approaching (mainly physical domain) nominal metaphor, has proposed a means of integrating salience information into hierarchically organized knowledge representations, while implicitly representing prototypicality. As a starting point, she refers to Ortony's (1979a, 1979b) theory of how salience and asymmetry function in human metaphor processing--in particular, that nominal metaphor is based on predicates which are of high salience for the vehicle and low salience for the topic.

Weiner's definition of salience assumes a taxonomic structure of concepts with the most general at the top of the hierarchy and the most specific at the bottom. A salient predicate, then, is one that implies inherent prominence (e.g., great size) or separation from other concepts in the hierarchy (cf. Winston's "extreme value" and "distinction with respect to a class," to be discussed). The hierarchy distinguishes properties that are peculiar to the concept itself (and more likely to play a critical role in the metaphor) from those due to its position in the hierarchy (cf. Kilpatrick's illustrative frame, in which "accuracy" and "shot pattern" are specific stereotypic properties of a "blunderbuss," but the capacity of "blunderbuss" as a "weapon" can also enter into a metaphor). Also, the incongruity which serves as a basis of a good metaphor can be easily determined from such a hierarchy. For instance, "Penguins are (like) wolves" is more metaphoric than "Dogs are (like) wolves," because "dogs" and "wolves" have a shared superordinate, namely, "canines."

Under this scheme, "apples" are represented prototypically as in Figure 3. Here the Value/Restriction, or $\mathrm{V} / \mathrm{R}$ (on the Role COLOR) RED is ranked as more typical than GREEN, and the lower Concept DELICIOUS is ranked as more typical than GRANNY SMITH, where both DELICIOUS and GRANNY SMITH impose restrictions on the COLOR of APPLE. RED and DELICIOUS, then, represent a prototype used in processing 
the metaphor "Jane's cheeks are (like) apples."

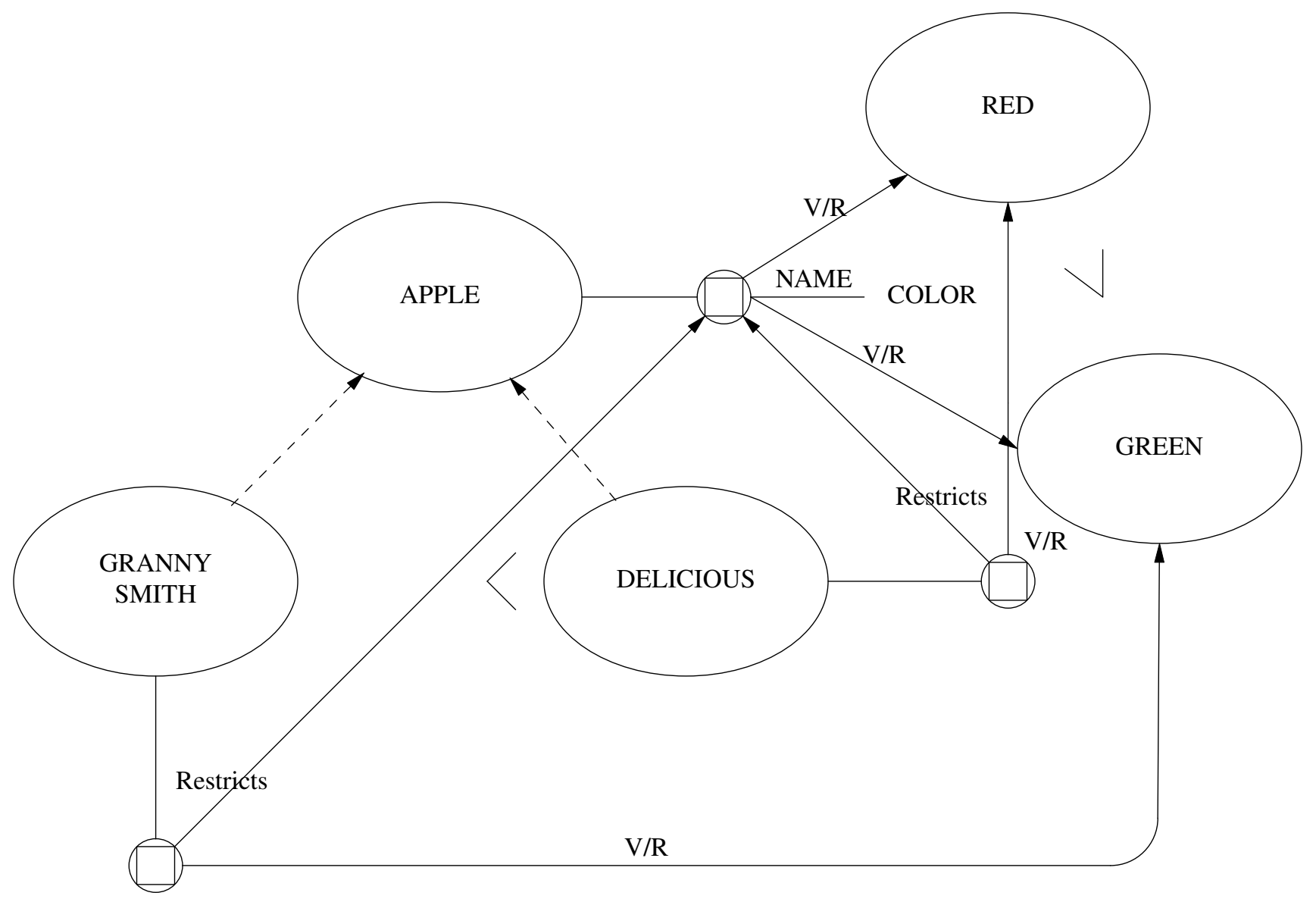

Figure 3. Weiner's representation of the nominal "apple". Note. From "A Knowledge Representation Approach to Understanding Metaphors" by E. J. Weiner, 1984, Computational Linguistics, 10, p. 11. Copyright 1984 by Association for Computational Linguistics. Reprinted by permission.

Weiner adds, aside from tools to represent prototypicality, a value range as a possible value restriction and a salience measure as a role parameter. Thus "hand" has a TEMPERATURE value range of 3 to 6 , and the TEMPERATURE of "ice" has a (colder) value of 7 and a salience value of 1 , where the possible salience range is from 0 to 1. Since JOHN'S HANDS does not restrict the Roles of the Generic Concept HAND, "John's hands are (like) ice" can then be recognized by the system as (a) a hyperbole, because the V/R for the Role TEMPERATURE is extreme in the vehicle but not in the topic and (b) a metaphor, because the vehicle and the topic do not share a proximate superordinate in the taxonomy. Raising the salience of the TEMPERATURE Roles of the topic thus gives the information that John's hands are extremely cold relative to normal hand temperatures.

Some aspects of this procedure are directed toward determining metaphoricity and the "goodness" of a metaphor, rather than an interpretation of it. In any case, Weiner does have a specific means of formally incorporating prototypicality and salience measure into a general organized knowledge base and thus into interpretations. Along with most of the preceding researchers, however, Weiner, in focusing on physical domain metaphor, has not considered the transfer of affective relations or a means of analyzing the meanings of salient properties themselves as they are transferred to the topic. 
Winston (1978) also treats mainly physical domain nominal metaphor. However, in contrast to those preceding approaches that deal explicitly with salient properties or types of salient properties, he introduces a theoretical rationale for determination of salience for nominals. In the course of his work on learning, he has arrived at some principles that aid the selection of potentially salient properties from a frame definition of all the properties of a metaphorically used concept, namely, importance of a property, extreme value, and distinction with respect to the class of the object. (Weiner has integrated the latter two into her representations.)

Winston uses these principles to hypothesize "transfer frames" that act as tentative "filters" for properties to be transferred from the source to the target concept. An example of a source frame for "fox," consulted for the metaphor "Robbie is a fox," is given in Table 3.

Table 3

Examples of Winston's Frames for Nominals.

Source frame for "fox":

\begin{tabular}{lll} 
FRAME NAME & SLOT & VALUE \\
\hline FOX & A-KIND-OF & SMALL-MAMMAL \\
& COLOR & RED \\
& CLEVERNESS & VERY-HIGH
\end{tabular}

Source frame for (specific) "box":

$\begin{array}{lll}\text { BOX-1 } & \text { A-KIND-OF } & \text { BOX } \\ & \text { COLOR } & \text { GREEN } \\ & \text { MATERIAL } & \text { WOOD } \\ & \text { PURPOSE } & \text { STORAGE } \\ \text { PURPOSE } & \text { A-KIND-OF } & \text { FUNCTIONAL-PROPERTY } \\ & \text { IMPORTANCE } & \text { VERY-HIGH }\end{array}$

Note. From "Learning by Creating and Justifying Transfer Frames" by P. Winston, 1978, Artificial Intelligence, 10, pp. 151, 155. Copyright 1978 by North-Holland Publishing Company. Reprinted by permission.

The transfer frame then includes CLEVERNESS: VERY-HIGH as an extreme value. Table 3 also shows that the PURPOSE of a (here specific) "box," namely STORAGE, is "globally important" and is thus included in the transfer frame. Existing properties of the target concept derived from memory and the discursive context are then used as filters to select among transfer frames and thereby decide what values actually get passed through to the target.

Winston restricts himself to simple nominal metaphor in which salient properties can be transferred without further analysis. His principles, however, represent subjective aspects of vehicle meanings and as such are of use to any approach directed toward affective connotations, as will be seen. 
In summary, none of the above work explicitly distinguishes experiential or subjective factors in theory or implementation. Several researchers, however, specify various aspects of the task of determining salient properties in general. In particular, Weiner integrates prototypicality and salience into a representation system in which hierarchic relationships between concepts are exploited; Carbonell ranks specific types of properties as to probable salience; and Winston gives general characteristics of salient properties.

These approaches are all of value to metaphor analysis. Yet in the absence of deterministic semantic analysis of the metaphorically used concept, they do not yield target domain interpretations in terms other than ambiguous source domain words. In confronting these issues, the approach described in the following sections uses both salience classifications and semantic analysis to proceed toward a working model which is potentially useful to metaphor research.

\section{FRAMEWORK OF A METAPHOR ANALYSIS MODEL}

It seems reasonable to consider verbs before nominals in any formalization attempts, because nominals can be defined in terms of verbal and attributive properties, which themselves provide the ground of a metaphor. Thus, in the presentation of my system, a program description for verbs precedes that for nominals, though the preliminary theoretical discussion refers to both kinds of metaphor. The basis of the model to be described is the Metaphor Analysis Program (Russell, 1975, 1976), which produces analyses of syntactically simple verbal metaphor. This program relies on a semantic analysis which accounts for the metaphoric extension. In this section, the theoretical context and operation of the initial program are briefly presented.

\section{Analogy-Based Extension}

Searle (1979) maintains that a goal of a theory of how metaphor works should be to establish principles that relate the speaker's "utterance meaning" to the metaphoric expression. For verbal metaphors, such as "She poisoned the discussion" (Searle's "relational" metaphor and Miller's, 1979, "predicative" metaphor), Searle states that the principles which relate the utterance meaning to the metaphoric expression enable a listener to select a target relation or property by giving a respect in which the target and the metaphoric usage in its literal sense might be similar or otherwise associated. In the Metaphor Analysis Program, this "respect" of similarity is made explicit by isolation of the structure of a verb from its domain in the knowledge base. The structural components underlying the metaphorically used (source) verb are transferred to a literal (target) paraphrase of the sentence and therefore are common to the target relation and source relation. This "common ground" of concepts in different domains defines an analogy as perceived and/or created by the originator of the metaphor.

The term "analogy" as applied to metaphor usually calls to mind the lexical format " $X$ is the $y$ of $z$." The assumption underlying the above analysis, however, is that analogy can also be seen as implicit in semantic components of any metaphor in which an extended structure can be identified. Thus "drop," "lose," "forget" and "become bored" as defined in the Metaphor Analysis Program all share at least a "leave state" component. This view does not presuppose any psychological validity of reference to analogy in metaphor comprehension (see Hoffman, 1985). Rather, the characterization of metaphor in terms of analogy is used in the present model without any claims that humans process metaphor in this way.

In terms of a computer model, analogies can be stated in several ways (see Miller, 1979). One form of analogy conveyed by verbal metaphor is (metaphoric predicate IS TO metaphoric domain AS literal predicate IS TO literal domain\}. Thus in "The country leapt to prosperity," \{"leap-to" (start to have new locative state) IS TO physical (locative) domain AS start to have new possessive state IS TO control (possessive) domain\}. A corresponding analogy for the nominal metaphor "Encyclopedias are gold mines" is \{ (use) "encyclopedias" IS TO (receive valuable concept in) mental domain AS (use) "gold mines" IS TO (receive valuable concept in) possessive domain $\}$.

The model's focus on analogy-based extension implies a view that, for both humans and computer programs, a metaphor comprehension process is dynamic in relation to linguistic processing which directly links words to referents, as in the case of literal usage or frozen figurative usage. This is not to say that metaphor is deviant, or that literal sentence meanings are considered before metaphoric meanings. Rather, the view 
presented here implies that in novel metaphor, literal or familiar meanings of the vehicle words are at some point referred to in the analysis process. In other words, creative metaphor does represent something new and unfamiliar, but at the same time it is a normal linguistic phenomenon.

\section{Program overview}

As a component of a language understanding system, the Metaphor Analysis Program would typically be activated by domain inconsistency between the verb of a simple sentence and its contextual nominals. The nominals are first mapped into a structural verb representation which is abstract (i.e., it excludes domain-specific properties such as physical instruments and the character of associated objects) and is therefore extensible. The resulting representations, together with an indication of the target domain category as determined by contextual nominals, comprise the intermediate target representation. From this representation, the program generates a paraphrase which either (a) includes a new target domain verb in the structure-determined category of the vehicle verb (not always appropriate because of insufficient discriminating properties) or (b) lexically maintains the separation of domains from extensible components. The intermediate representations could alternatively be converted to concept-level symbolic target representations usable by a host language understanding system and related to the knowledge structures of that system. Figure 4 gives a global overview of the procedure.

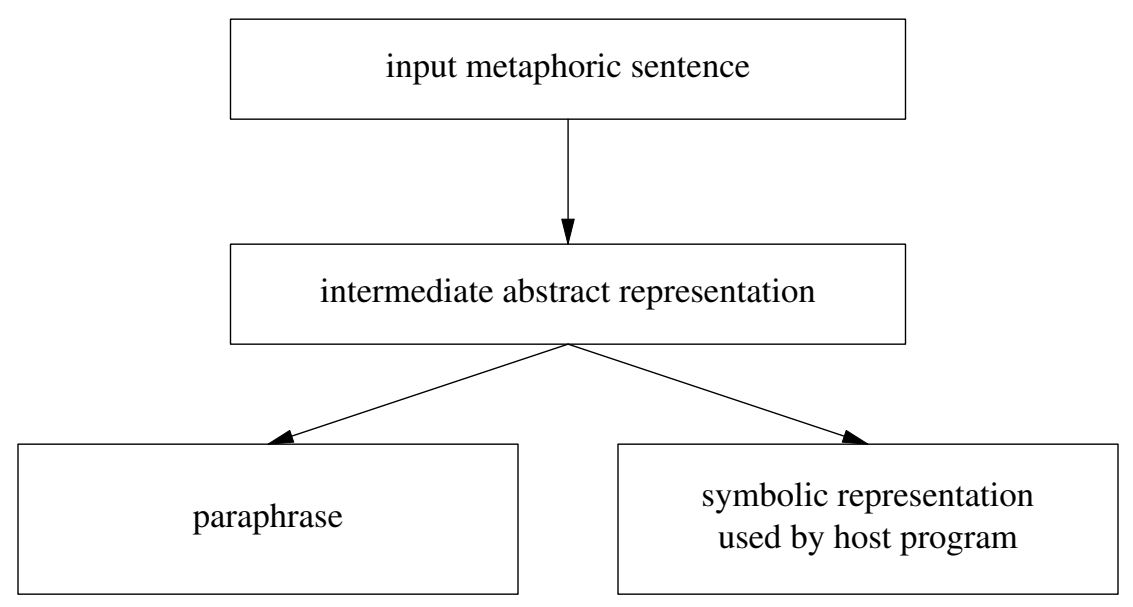

Figure 4. General operation of the Metaphor Analysis Program.

Thus the physical domain metaphoric (stylized) input "carpet drink ink" is paraphrased as "ink start to be in carpet." The abstract metaphor "country leap to prosperity" is paraphrased as "country suddenly start-to be prosperous" or alternatively, "country suddenly start-to have economic-control concept (i.e., wealth) high amount."

The interpretation capabilities of this or any procedure intended to account for metaphoric extension depend on two concerns described previously, namely (a) the form of representation of the salient factors extended from the vehicle and (b) a means of selecting such factors. As is evident in the next section, these tasks may be interdependent for verbs, since once components are abstracted from an (unambiguous) verb sense, they are always transferred in metaphoric extension and are by definition salient. 


\section{REPRESENTING VEHICLE CONCEPTS}

\section{Verb Factors}

The assumption that metaphor is used for particular nondeclarative purposes suggests semantic definitions of verbal vehicle concepts that include connotations represented as the import or effect of the concept. Each verb representation should include (a) potential effects on one who is undergoing the process represented by the verb, and (b) potential impressions on the recipient of the metaphor.

Verb representations which incorporate these experiential effects can be characterized in terms of "explicit" and "implicit" factors. The state or resultant state predicated by the metaphor is by definition explicit and, as an "end-state," can be thought of as a (non-experiential) effect. ${ }^{2}$ To be (literally or metaphorically) alive, for example, is an inherent result of being born, and therefore an explicitly conveyed part of a "be born" predication.

The indicated experiential effects, along with elementary (non-experiential) components that characterize the action of a verb, represent implicit factors. The importance of retrieving experiential factors in metaphor analysis has an analog in the computer analysis of nonmetaphoric language. For instance, Schank and Abelson (1977) point out that words often have connotations that can be formalized computationally as goals in conjunction with conceptual structures. Thus "kiss" is associated with a certain quality of relationship, or attitude (Case a) that can be ascribed to the one who kisses. Computer programs must extract such connotations from the word, if they are to make inferences similar to those a human would make upon encountering a usage of "kiss." Sloman and Croucher (1981) and Dyer (1982) also note the importance of affects in conveying information about goals relevant to computer comprehension of narratives.

The effect described by Case $b$ is an implicit factor that is not only affective (as in the preceding example) but also subjective. Subjectivity in nonmetaphoric language may take the form of what Breal (1900/1964) called a "dialogue with the reader," as in "He has no doubt (or certainly) arrived." Schank (1972) confronts a similar phenomenon in the area of automatic text comprehension by correlating adverbs with beliefs of the speaker. Other nonmetaphoric examples with different grammatical formats are "the dubious notion" and "she knows (vs. believes) that...," where the verb "know" implies that the originator shares the belief. In metaphor, subjectivity often takes the form of evocative connotations that reflect the originator's attitude toward the expressed situation.

The assumption underlying the model presented here is that all of these implicit effects are introduced metaphorically by way of vehicle experience which the originator hopes the recipient will share. Thus, through an appropriate vehicle definition, a metaphorically used verb can be analyzed by a program in terms of extracted intentions and attitudes, which it then associates with the actor of the verbal concept and/or the recipient of the metaphor. Such experiential factors constitute symbolic effects (unrealizable in the absence of a physiological body) intended by a goal-directed originator. This approach allows for representation of Paivio's (1979) "mediational response" and is consistent with Verbrugge's (1980) call for the inclusion of affects in semantic description. The observation that such an extensible attitude can be expressed as an effect on particular animate nominals also builds on Gentner's (1980) theory that (complex) structures or relations, including affective relations, rather than (simple) attributes are principally extended in metaphor. That is, it is not only relations between parts of the vehicle concept which are extended in metaphor, but also the relationship between actors or speakers/writers (e.g. Romeo) and the vehicle concept (e.g., Juliet as "the sun"). A formalization of these attitude components or mediational responses is a step toward identifying the role of subjectivity and intention in metaphor.

For purposes of extension, then, a verb definition can be organized in terms of factors, independent of domain, as shown in Table 4.

\footnotetext{
2 A resultant state is essentially a "RESULTATIVE inference" as defined by Rieger (1975), as well as one of the "case-based inferences" used by Wilks (1977b, 1978).
} 
Table 4

\section{Extension-Oriented Organization of Verbal Concepts}

I. Explicit (predicated information, such as resultant state)

II. Implicit (modifying information referring to specific components)

A) Verb qualifiers, such as repetition

B) Attitude or response of participant, such as effort

C) Response of recipient in terms of emotions in diluted form, such as fear

Examples of how some individual components describe explicit and implicit effects are the following: for "The legislature hammered at the proposal," a verb factor is "repetition"; for "She glided to the presidency," the response of the participant is "without effort"; for "The legislature guillotined the proposal" the predicated effect is that "the proposal is no longer functional," and the response of a recipient is one of "shock" or "sudden fear," as intended by the writer. As effects, all these factors are extended to the target representation in the analysis program. Since responses are formally related to specific components of denotative structures, the computer program has a way of drawing inferences concerning these components in further information processing. Without this capability, for instance, a program could not make adequate sense out of the text, "He plowed through his memories; she glided through the same ones." In short, we have the beginnings of a way to deal formally with vague feelings about metaphorically used concepts.

\section{Extension: Abstract Components and Conceptual Domains}

Given this factorization of verbal concepts, how can we formalize verb constituents in a way that allows their correct integration into the target domain? To look at an illustrative case, Smith and Montgomery (1982), in their study of verbs used in sports headlines, considered whether there is any limit or pattern to the different ways sports writers can describe winning and losing. They pointed to a semantic category of verbs representing "barely winning" or "not losing" in the context of sports headlines ("elude," "sidestep," "hold off," "repel," "hang on," etc.), namely "avoidance of destruction." A program must recognize the category of a metaphorically used word, if an analogous term is to be chosen for target-domain expression. The identification of the same predefined category for all verbs in this example, however, proceeds partly from knowing in advance how the verb is used metaphorically. To allow for verb differences that become evident apart from the sports context (among the listed verbs, "hang on" is alone in not including an adversary in its immediate semantic context), verb definitions should be based on abstract components rather than on explicit categories. Paraphrases based on component representations often seem too general; they can be made more specific, however, if the representations are combined with expectations of the target domain to provide a symbolically "merged" representation. For instance, the analysis program could extract a "loss of control" component as an explicit effect from a metaphorically expressed sports verb; the generation of a more specific word, such as "defeat," however, would be based on a relationship between "loss of control" and "defeat" in a sports domain "script" (in the sense of Schank \& Abelson, 1977) and perhaps also from knowledge that headlines describe end results. The described procedure itself would thus be "unaware" that "Cosmos stun Teamen" implied ultimate loss of the game by the Teamen, but would in fact contribute to this interpretation.

Consistent with the preceding outline of predicated and modifying components, the abstract representation of a verb has as its core structure a state predication, together with optional causation by an agent. Although the verb definitions are case-like in the way they map input syntax into internal concepts, this system unifies and reduces cases to two in number. These "cases" correspond to state representations which are similar to logical one-argument predicates for attributes and two-argument predicates for relations between objects. As in Gentner's (1975) use of the representations of Norman and Rumelhart, the verb structures of this system are similar to but more reductionist than Schank's Conceptual Dependency representations (1975), which link actors, objects, and primitive acts together in "conceptual case" relationships. That is, consistent with the indicated case reduction, elementary concepts, such as change (e.g., LEAVE-STATE), as well as (non-extensible) domains, are factored out of Conceptual Dependency structures. Thus the identity of factors common to 
metaphorically used verbs and any existing substitutes literal for other domains can be realized in the verb representations. In contrast to the word-oriented analyses used by some of the previously cited researchers, the representation components themselves comprise a relatively small (slightly redundant) set of "primitive" ${ }^{3}$ elements (see Appendix).

In terms of information processing, we can view abstract verb structures, together with affective components, as the ground of a verbal metaphor which is extended from one domain to another. To determine whether metaphoric extension is in fact present, a program must be able to recognize a domain difference between the verb and a dependent (usually adjacent) nominal, so that the structure of the verb can be extended to the domain of the nominal in what can be viewed as a disambiguation process. For instance, the sentence "The idea blew up" does not mean that the idea literally (physically) blew up, because "idea," unlike the literal sense of "blew up," is not physical.

For each verb in its literal sense and for each nominal, therefore, a domain must be defined. (If the literal domain is uncertain, the choice of domain is not critical. The choice merely determines whether an assimilated metaphoric expression is interpreted in its intended target domain by extension mechanisms or as a literal usage.) Consideration of a domain taxonomy is tied specifically to general usages of verbs (e.g., "carry"), rather than to verb phrases (e.g., "carry the ball"), which might convey specific domains of cultural activity. A metaphorical usage is therefore determined by a difference in conceptual domains or modalities (referred to as "levels" in previous work) rather than in specific domains of world knowledge such as sports. Domains that have been incorporated are as follows:

PHYSICAL-- ANIMATE, INANIMATE (various spatial relations)

MENTAL-- INTELLECT (i.e. FACTUAL or PROPOSITIONAL), ATTITUDE, VOLITION

SENSORY-- SIGHT, SOUND, and so on

CONTROL--INTRINSIC (= personal), EXTRINSIC

(EXTRINSIC CONTROL of OBJECT $=$ economic,

EXTRINSIC CONTROL of ACTION = political)

"Winning" and "losing," then, are INTRINSIC-CONTROL verbs. A corresponding set of domains for nominals additionally distinguishes TIME and SPACE nominals. Although many metaphors appear to be extensions from a PHYSICAL or CONTROL level, other extensions are possible (Russell, 1976).

For consistent extension of explicit effects for all domains, the multidomain character, e.g. of "team," must be represented. Thus, if the sentence "The Swiss Guards' team pulverized the Uffizi Librarians' team" is to be analyzed metaphorically (i.e. if the possibility that a team is physically "pulverized" is left aside), then the program must recognize that a function or quality of the team is the actual underlying object of pulverization. The predicated effect of "pulverize" is then consistent for both literal and various extended usages --the affected object no longer exists or functions. In the output analysis of the given example, then, the strategies used by the Librarians' team cease or no longer function.

\section{Extension of Experiential Factors}

Sports-headline metaphors are notable as subjective rather than objective descriptions of an event. This is because, as Smith and Montgomery (1982) pointed out, many factors are involved in the creation of a sports headline, including variety and cleverness (puns, alliteration, etc.). Subjective experiential factors play a particular role. For example, Smith and Montgomery's research correlated a certain vaguely defined category of verbs ("pulverize," "crush," "stun," etc.) with the case of winning by a large margin or in an upset. The verb

3 The idea of "extensible primitives", whether seen as structures, features or affects is arguable, of course, and some reveal their own metaphoric character. Wilks (1977a) maintains that primitives serve as a useful organizing hypothesis rather than as justifiable components. Consistent with this position, it is being claimed here only that some such terms are necessary for metaphor analysis, and not that they either have some inherent validity or imply the possibility of truly literal interpretation of metaphor. 
thus reflects reader expectations rather than the state of the team that is "pulverized," which need be no different from that of a team that is "left in the dust." That is, while a team may experience defeat, reversed expectations and effort, it does not necessarily experience a sense of being pulverized, ravaged, demolished, guillotined, ${ }^{4}$ or any other of the multitude of verbs chosen by the sports writer as a result of his own (or of conventional) feelings or expectations and the goal of entertaining. It is the recipient of the metaphor who is intended to experience the intensity, surprise, etc. implied by the verb.

The emotions used to describe implicit effects are considered to be extended to all domains literally (though with diminished intensity), rather than analogically. No commitment has been made to any particular vocabulary of emotions. However, as further examples of their incorporation, "recoil" includes the specification PARTICIPANT (OBJECT: FEAR, DISGUST), in which "OBJECT" represents the one who recoils, "guillotine" includes a RECIPIENT: FEAR specification, and "be born" includes RECIPIENT: AWE. In addition to a simple affective response, an implicit affect-related goal, formulated as a proposition or belief, may also be defined in association with the vehicle verb. ${ }^{5}$

\section{Examples}

The examples given here partially illustrate how some of the defined components enter into verb representations. For instance, in the abstract part of the definition of the verb "plow through" (see Table 5), the "plower" is the conceptual OBJECT in the process of (TRANS: THRU-STATE) changing its locative relationship (OBJECT AT LOCATION), and FORCE: HIGH represents effort, difficulty or resistance as an implicit effect on the OBJECT.

Table 5

Extensible Frame for the Verb "Plow through."

$\begin{array}{lll}\text { STRUCTURE: } & \text { (STATE-TYPE: } & \text { OBJECT AT LOCATION } \\ & \begin{array}{l}\text { ROLE: } \\ \text { OTHER: }\end{array} & \text { OBJECT } \\ & \text { TRANS: THRU-STATE) }\end{array}$

Many verbs have more complex underlying structures than "plow through," and require nesting, negation, or the use of closed-set connectives such as "purpose" links. However, the above very minimal representation is sufficient to process the input sentence "He plow(s) through (his) memories" as a component-based representation which can be read as "He mentally with effort continuously slowly processes his memories" (see Russell, 1982, for additional processing needed to handle constraints on nominals). For the sports headline input "Eagles hang on," a FORCE: HIGH component attached to "Eagles" represents effort, and negation of the loss of control is represented by

NOT TRANS: LEAVE-STATE (OBJECT AT LOCATION), where OBJECT = INTRINSIC-CONTROL and LOCATION = "Eagles." These components provide a basis for the paraphrase, "Eagles with effort avoid

${ }^{4}$ Some of these verbs are so close in their effects that it is dubious whether even human recipients distinguish their responses to such usages, except perhaps to entertain different vehicle images of the sports writer's description. In this sense the sports writer's choice is clearly arbitrary.

${ }^{5}$ These responses and goals can be linked with information and inference mechanisms used in computerized nonmetaphoric text comprehension. The representation of situations associated with affects by Dyer (1982) provides a compatible means of supplying such information; three of Dyer's abstract structures representing emotional reactions--evaluation (POSITIVE, NEGATIVE), character experiencing the emotion and (scale of) intensity, are similar to those used in the Metaphor Analysis Program. 
losing control."

Under this system, verbs defined in terms of similar abstract components in different domains are theoretically interchangeable for purposes of roughly equivalent metaphoric or nonmetaphoric expression. In an interpretation, if no literal verb exists which includes all the implicit components defined for the metaphorically used word, these components are added to the paraphrase. For example, "siphon off" would be defined by the knowledge base editor with a (+) CONTINUOUS verb descriptor. "Employers siphoned off their rights" could then be paraphrased as "Employers continuously (or gradually) took away their rights." Similarly, a paraphrase of "Employers whisked away their rights" would refer to the SPEED: HIGH and RECIPIENT: SURPRISE components of "whisk away," giving "Employers quickly and surprisingly took away their rights." If, in addition, in defining "siphon off" and "whisk away," the editor associates with the agent a goal of not wanting the possessor of the affected OBJECT to be aware of the action, and/or a RECIPIENT response of DISAPPROVAL, then these connotations are transferred to the output representation.

Such approximate analyses are certainly inadequate to fully describe the experience of plowing, hanging on, or siphoning off (literally or metaphorically); some discriminating detail is lost along with the specific nature of the experience. However, without recourse to ad hoc mechanisms, they do provide both informative general components suitable for integration into the target domain and connotations (such as "effort" as opposed to "enjoyment" in "plowing") essential to comprehension of the situation.

\section{Representing Nominals through Verbal Predicates}

Nominals as potential metaphoric vehicles can be defined in terms of properties or predicates that are candidates for metaphoric extension. For example, the meaning of "The sun is a magician" focuses on the verbal concept "transform" as derived from the function (job, role) of a magician; and the predication underlying "The moon is the Rosetta Stone of the planets" (Jastrow, 1947) is based on "decipher in order to discover."

To account for metaphoric extension, the predicates must be formulated in terms of an extensible representation vocabulary such as the previously described abstract components determined for verbs. Thus "magician" is represented through change-of-attribute components and a RECIPIENT response of SURPRISE. "Rosetta Stone" is represented by change (= translation) of SENSORY-SIGHT concepts (= symbols) and use of the changed concepts in order to have MENTAL-INTELLECTUAL concepts; the RECIPIENT response is less stereotyped than for some concepts, but is in any case some attitude (e.g. INTEREST) with a POSITIVE connotation. With a specific indication of how both verbs and nominals can be represented, we now turn to the second part of the analysis task, namely, the determination of what is represented.

\section{IDENTIFYING SALIENT PROPERTIES OF NOMINALS}

Whereas most verb senses are not ambiguous with respect to their perceived properties, for nominals, the identification of properties to be transferred to the output representation is a core problem. Before pursuing this task, we will look briefly at vehicle properties in the context of the nominal metaphor as a whole.

\section{Topic, Vehicle and Common Ground}

Miller (1979) formulated a theory of nominal metaphor in terms which posit a similarity between different properties of topic and vehicle. Searle (1979) claimed that this view "assigns an impossible computing task to the speaker and hearer" (p. 111). Without entering a debate on Miller's theoretical position on metaphor, we can point out how the extended Metaphor Analysis Program could in fact implement Miller's formulation.

First, it must be said that, in the program, the "similarity" between properties of the vehicle and of the topic of the metaphor is assumed to be imposed by the originator, rather than to exist a priori (cf. Lakoff \& Johnson's 1980 structuring of the topic by the vehicle). This assumption, as Verbrugge (1980) observed, is more likely to hold for novel than for trite or less creative metaphors. In any case, in the present program, which is focused on abstract rather than physical domain metaphor, a verbal representation resulting from analysis of the vehicle is simply transferred to the topic. Thus, regardless of whether a partial match exists between topic and vehicle properties in the knowledge base, the program interprets "Tide pools (supermarkets, dumps) 
are gold mines" analogously to "Encyclopedias are gold mines" (Russell, 1982, 1985). ${ }^{6}$ Miller's similarity between different properties is exhibited in the output, in that obtaining something valuable from a tide pool or supermarket is certainly different from obtaining factual knowledge; yet if the domain-specific objects themselves are removed, there remain identical components reflecting structures that are perceived as similar (TRANS: ENTER-STATE, OBJECT AT LOCATION, EVALUATION: POSITIVE, which can be interpreted as "start to have something, with positive evaluation").

In this kind of analysis of a nominal metaphor " $X$ is $Y$," the program in effect replaces the metaphoric vehicle by abstracted components. The process reflects the view that the word "is" (or a similar copula link) differs from its (literal) propositional or declarative sense as defining a superset, subset, or identity. ${ }^{7}$ The metaphoric "is," consistent with the nature of metaphor as a tool of intention, is instead a suggestion to abstract from one's own experience of the vehicle. As Honeck, Voegtle, Dorfmueller, and Hoffman (1980) state, metaphors and proverbs "provide a means of focusing on salient aspects of complex events" (p. 132). One could go further to claim that metaphors do this in place of declaring identities or other set relationships. There is thus no question of a "truth value" of a metaphor until properties derived from the effect of the vehicle on the originator are applied to the topic as literal inferences. However, the metaphor may fail because the recipient does not share the experience that the originator uses as a vehicle. In a program, the choice of salient properties of the vehicle is what determines whether the program will model conventional understanding of the metaphor vehicle and thus succeed in adequately paraphrasing the metaphor. This selection process will now be considered.

\section{Constraints and Subjective Meaning}

Interesting nominal metaphor does not usually depend simply on surface properties of the nominals. Since denotative structures for nominals are not apparent as they are for verbs, the relevant meaning of nominals, even more than of verbs, is given in terms of their potential effects on people who relate to these concepts. For artificial objects, the most obvious effect is the function of the object (Russell, 1975, 1982; cf. Rieger's FUNCTION inference, 1975), together with any associated affects. Thus, as previously illustrated, it is most likely the use, potential, or function of a "gold mine" rather than any physical aspects which provides the ground of an isolated metaphor. For natural objects such as glaciers, such a function is what the object typically does and what we notice when we place ourselves in the picture (e.g., advancing and receding). Representations of persons are based on their functional roles or well-known actions (e.g., "He is the Henry Ford of organized religion"; Janssens, 1981).

More generally, a nominal must be defined in terms of how it is typically related to, if a program is to represent what the nominal means when used metaphorically. It is this type of information that can at least partially resolve difficulties seen (e.g., by Carbonell \& Minton, 1983) in the computer interpretation of "Sally is a block of ice." In other words, physical properties of "ice" do not supply any metaphoric ground applicable to "Sally," but the inference that one does not get too close to "(a block of) ice" does.

${ }^{6}$ There are, of course, constraints imposed by the topic with respect to comprehensible interpretations. (In the verbal metaphor program, a small set of abstract features of nominals is used to determine whether dependencies or relations within the generated analysis are literally or metaphorically "conceivable.") Thus "Knives are gold mines" is not an easily comprehended metaphor, because one cannot obtain anything directly from a knife. However, these constraints do not necessarily select properties from the vehicle. The procedure for a language analyzer here would be not to force other, less salient aspects of "gold mine" into the interpretation, but to look to the discursive context for a possible referent which resolves the synechdochal use of "knives" (e.g., "investment in knives"). The point is that salient properties of a vehicle of a novel abstract metaphor are often so strong that they are not given up in favor of other vehicle properties.

${ }^{7}$ Ortony (1979a, 1979b) supports his claim that no special process is needed to comprehend metaphor by reducing the problem to one of feature salience imbalance. Thus "Encyclopedias are books" is a literal statement, because "encyclopedias" and "books" share highly salient features (attributes or predicates), but "Encyclopedias are gold mines" is a metaphor, because features which are of high salience for "gold mine" are of low salience for "encyclopedia." However, this description, as Weiner's (1984) knowledge organization scheme illustrates, reflects the fact that "encyclopedias" and "books" are in a superset relationship, whereas "encyclopedias" and "gold mines" are not. Although the processes to interpret both types of examples can be unified, it cannot be claimed that there is no difference between the processes, since links between topic and vehicle are direct and indirect respectively. 
The knowledge base editor must therefore analyze the nominal in terms of how most people perceive the concept (cf. the storage of stereotyped properties directly with the vehicle nominal by Kilpatrick, 1982, and Weiner, 1984). This focus on subjective properties specific to the vehicle concept requires a special mode of observation, which perhaps includes thinking of concepts in terms of "affordances" (Gibson, 1977) or in terms of how they are perceived by or related to an animate observer. The editor must posit general experiences involving that concept, if components critical to metaphor interpretation are to be successfully extracted.

If this means envisioning every possible experience with the concepts, we are lost; however, it does not. To paraphrase Johnson and Malgady (1980), it seems reasonable that we could make some judgment about how an individual might experience metaphorical usages of concepts for which highly salient characteristics--in terms of properties and affordances--are identifiable. If this is true, we can assume that formalizing such judgments in programs will result in paraphrases of metaphor which may correctly refer to the originator's intended attributions to the topic. Such judgments, in the form of stereotyped properties and connotations, are stored as potentially salient for the purpose of metaphor, and are thus made available to the program mechanism for transfer to the output representation. But how can an editor be systematic in arriving at a conventional experience of the vehicle? If the extraction of salient factors from a potential multitude of such associations is to be constrained, a look at reasons for salience is relevant.

A human or computerized procedure for selecting salient factors is not obvious. For example, if we are defining a word such as "glacier," we might think of properties such as "cold, usually high, slowly advancing or retreating, massive, dangerous (slippery, having crevasses)," and "inexorably moving." By itself, an ad hoc list such as this does not tell us what the word "glacier" might mean when used metaphorically. Recourse to the nature of metaphor as subjective, however, can be of use in defining concepts in the knowledge base; an editor knows that, although "cold" is a property of a glacier and should be kept around for extended metaphors, it does not readily present itself as an answer to the question, "What strikes you about a glacier?" Thus it can be expected to be of low salience in isolated metaphors. What the editor needs is a set of criteria which points to what is "remarkable" about concepts.

As reviewed in the introductory discussion on artificial intelligence work, Winston (1978) specified three such criteria in connection with nominal definitions consisting of simple attribute-value pairs: (a) extreme value, (b) distinction with respect to other members of the same class, and (c) importance. As concerns both our analysis and the nature of metaphor, these criteria for salience are justified in that they are all subjective, relative descriptions which "mean" something or "have an effect"; we notice and are affected by that which is extreme, that which is different, and that which is of concern to us. Winston's system selects properties from a frame definition of a vehicle concept by a filter based on these three criteria. In the system presented here, which is developed specifically for metaphor analysis, the editor acts as a filter in using these criteria as a guide to "remarkable" subjective properties specific to the nominal being defined.

A potential further aid to salience identification in the analysis of metaphoric phrasal and prosodic input is the immediate context of the metaphor as indicated by the syntax. For instance, the locative phrase "on the glacier" implies proximity and the possibility of direct perception, and would therefore determine that the "danger" and "quiet" properties are relevant. However, if "glacier" is an actor, as in "The glacier is accelerating," then the perceived typical action of a glacier--its advancing or retreating--and the corresponding descriptors "slowly, repetitively," and "inexorably" become relevant.

The contributions of these different types of immediate context suggest an initial organization of metaphor-oriented definitions of nominals as shown in Table 6. 
Table 6

Partly Formalized Definition of the Nominal "Glacier."

\begin{tabular}{|lrl|}
\hline Perspective & Salience Criteria & Properties (Unformalized) \\
\hline glacier is object & $\begin{aligned} \text { (extreme value): } \\
\text { (other): }\end{aligned}$ & $\begin{array}{l}\text { large } \\
\text { high }\end{array}$ \\
glacier is actor & (distinct): & advance, recede (slowly) \\
& (important): & cannot be stopped \\
(other): & change shape of land \\
& produce water \\
glacier is environment & dangerous (deceptively) \\
& (important): & cold \\
& still
\end{tabular}

This scheme implies that for a sentence in which "glacier" is serving as an actor, the typical actions of a glacier provide a first choice for salience. A formal representation of the slot-fillers for the "advancing and receding" action of a glacier is illustrated in Table 7.

Table 7

Components Describing a Property of the Nominal "Glacier".

FUNCTION/ TYPICAL ACTION:

((TRANS-ENTER-STATE (OBJECT AT LOCATION)

THEN

TRANS-LEAVE-STATE (OBJECT AT LOCATION))

CONTINUOUS

REPETITION

SPEED:LOW

(RECIPIENT:) ? FEAR:LOW)

Thus whatever is metaphorically described as acting as a "glacier" will receive a provisional analysis corresponding to "repeatedly entering and leaving a state, continuously and slowly, and possibly evoking a low amount of fear (= concern)." The conceptual domain is derived from the topic as indicated in the input text.

According to this system, salience principles, immediate linguistic context, and objective and subjective properties of the vehicle itself all participate in the computerized identification of salient properties for particular usages of metaphor encountered in a text. Salience principles operating on the possible properties of a 
concept implicitly impose a partial ranking. For example, in terms of Carbonell's invariance hierarchy, natural tendencies ("advancing/receding") precede object description ("large"). However, it is the distinctiveness or prototypicality of the "advancing/receding" property of a glacier which suggests it for metaphorical usage. By contrast, if a property is not distinctive for the concept, it is not a good candidate for the intended salient factor of the vehicle. For example, the natural tendency of a jungle (i.e. to "grow") should not automatically take precedence over an object description (e.g., "complex"), in spite of its relative position in the hierarchy. An advantage of the system described here is that salience principles select properties which humans perceive as not only salient to but prototypical of particular concepts, such as "high" for a mountain but not for a (similarly high) glacier.

\section{An Example in Discursive Context}

The preceding section presents a basis for systematically storing in the knowledge base a relatively small amount of information representing salient aspects of vehicle nominals. ${ }^{8}$ In discursive context, potentially salient properties may be further constrained by words which refer to certain of these properties. What then do the relatively minimal representations produced by the above system contribute to a computer interpretation of a metaphor in context? A simplified analysis of a prosodic metaphor may suggest what kind of output is derivable from the described minimal representations in interaction with surrounding text:

If political glaciers ever accelerate, this now seems the time: The slow movement toward an end of the Bonn coalition, still uncertain, still arrestable, has nonetheless become visible to everyone.

The Christian Democratic victory and the heavy Social Democratic losses in state parliamentary elections in Lower Saxony removed the need for fine instruments of measure and left behind a rich terminal moraine of remarks and tactics. (Vinocur, 1982, p. 2)

Here the topic domain is indicated by "political" (CONTROL); that is, we have a "political situations are glaciers" metaphor. "Accelerate," a PHYSICAL concept, is a verbal predicate of "glacier" and is thus compared with the defined actions of a glacier, starting with its FUNCTION, (TYPICAL ACTION). That is, a representation corresponding to "move with speed gradually becoming greater" is partially matched with the "slowly advancing/receding" component as formalized in the given FUNCTION definition. This gives the information that some political situation is perceived as speeding up with respect to the norm. "Toward the end of the Bonn coalition" corresponds to the ENTER-STATE portion of the "advancing/receding" structure. LEAVE-STATE, REPETITION, CONTINUOUS, and LOW FEAR are expectations available for further confirmation or inference. Since there is no indication of direct contact with the glacier as an environment, factors such as "danger" are not considered.

In the following paragraph, the "fine instruments of measure" metaphor (through literal-language inferences) confirms that the movement of the glacier is easily observed visually. The Metaphor Analysis Program maps the structural part of this implication from the SENSORY and PHYSICAL domains into the somewhat redundant but reasonable representation MENTAL-INTELLECTUAL (TRANS: ENTER-STATE (OBJECT AT everyone)), where the "content" of this MENTAL-INTELLECTUAL OBJECT is EXTRINSIC-CONTROL-ofACTION (TRANS: ENTER-STATE (TRANS: LEAVE-STATE (OBJECT AT Bonn coalition))). A rearranged word-for-word paraphrase of this segment gives "Everyone start-to believe Bonn coalition start-to stop have political-control."

In the metaphorical phrase "left behind a rich terminal moraine of remarks and tactics," the topic is again directly indicated, namely, that of "remarks and tactics." Here "left behind a rich terminal moraine" does not add to the information provided by "remarks and tactics, " but does provide entertainment by completing the "glacier" image (see "change shape of land" factor in "glacier" definition), while conveying the writer's

\footnotetext{
${ }^{8}$ I have implemented a corresponding prototype PROLOG program to paraphrase isolated abstract nominal metaphor.
} 
desire to focus on the superabundance of remarks and tactics following momentous events. An interesting point with respect to the sometimes secondary nature of information and logic in metaphor is that readers might not even notice that when glaciers leave moraines, they are receding, not advancing (if the readers originally held the image of the advancing glacier, they would have to change their image).

This partial analysis draws only on salience selection criteria and representation components previously specified, along with inference mechanisms of the type already developed in the area of computerized nonmetaphoric text comprehension. Existing or imminent computer programs may or may not be able to "read" and "comprehend" a more literal version of the given text without encountering some unsolved problems. However, the metaphoric elements of this text, which go beyond mere physical similarity, can all be expressed in terms of simplified literal information. This has been done here without the need to create any new forms of representation, and without relying on identical lexical items to be retrieved from disparate domains.

\section{EXPERIENCE AND COMPUTER REPRESENTATION}

The preceding analysis suggests that a metaphor could be "understood" automatically to the extent that the information conveyed, including affective connotations, could be paraphrased in general terms. On the other hand, the writer's perception in all its detail (e.g., the caricature of political observers as scientists taking fine but presumably significant measurements of physical objects) could not be captured as a whole by such a process. This assessment is related to the observation that, as in the interpretation of many forms of artistic expression, the recipient must do much of the work, bringing individual experiences to the interpretation. The varying experiential aspects of a concept, such as a "glacier," can perhaps be illuminated through a metaphoric context in the domain of music that "describes" physical events (i.e., program music). In this kind of music, as in expressive linguistic metaphor, it is impressions or effects of objects or concepts which are of importance, rather than objects themselves. In Richard Strauss's Alpine Symphony, we hear experiences of sunrise over the mountains, entering a forest at the beginning of a climb, and arrival on a glacier. In the first two sequences, the listener can perhaps easily identify the corresponding experiences, component by component. For example, the subdued music conveys the stillness or remoteness of the forest.

However, as in the domain of language, one can assume that the virtual experience is much greater if the recipient has actually experienced these phenomena. This point is further brought out by the musical evocation of the experience of being on a glacier. This experience is not generally accessible; those who have not experienced the immediate environment of a glacier might be confused if trying to view the music as a description. One might hope the recipient did not succeed in this kind of prediction of the composer's intentions. The point here is that experience, understanding, and meaning are obviously different from description and that paraphrases of metaphor which are not themselves evocative of experience are useful for certain purposes but are of course not equivalent to the metaphor.

This apparent theoretical limitation arises from the nature of componential analysis. Something is lost when an analysis procedure relies on elementary components such as elementary states and changes of states. Vehicle representations might be sufficient to yield the inferences (including those on affective states) that allow for computerized text comprehension. However, a purpose of expressive metaphor is experience, and one cannot experience isolated chunks of information. The unique nature of each experience would seem to be inaccessible to representation by general or primitive components, because these are all merely abstracted from the experience. Similar limitations apply, however, to human analyses of metaphor. As MacKay (1969) points out, meaning is not always what the individual is able to say it is.

These conclusions can be related to Searle's (1979) answer to the question of whether all metaphoric utterances can be given literal paraphrases. Searle claimed that a paraphrase can reproduce the truth conditions of the intended metaphoric meaning, but not the semantic content which occurred in the listener's comprehension of the metaphor. This is in contrast to the view expressed by Paul (1972): that explanations of metaphor seem to be inadequate only because we do not really know what they mean. The described computational approach, which isolates factors of meaning, allows reasonable if not satisfactory automatic paraphrases of metaphors of an important class. Subject to running the described program with a large number of examples, it 
can be assumed that the general definition procedures and mechanisms which produce such paraphrases provide some evidence that we do know what metaphors mean. The reason for the inadequacy of interpretation may instead be that literal description of conveyed shared experience is inadequate simply because it is description. Consistent with Searle's conclusion about reproducing semantic content, this may define the limitations of human paraphrase of metaphor, and is certainly a theoretical limitation for computer programs as well. While recognizing this limitation and the infeasibility of entering all world knowledge into the knowledge base, we can say that research directed toward reasonable analyses is a theoretically and practically productive endeavor.

\section{METAPHOR REPRESENTATION AND LANGUAGE}

Metaphoric expression as it is being considered here occurs in the form of linguistic expression. Several relevant questions come to mind. How is metaphoric language or metaphoric representation specifically adapted to conveying experience of non-PHYSICAL concepts? How do the proposed computerized component-based processes and symbolic representations relate to the metaphor-nonmetaphor dichotomy--that is, in what sense, if any, are such representations metaphoric?

Because the semantic representations presented are structured in terms of primitives, the cohesion of the vehicle experience disappears, and the recognizable metaphoric character of the input expression is lost. However, since the representations include nonphysical or abstract concepts as objects or categories, they can still be considered metaphoric, reflecting illusions engrained in our language. Thus "be (attribute)"--for example, "be hopeful"--is expressed as the dead metaphor "have (object)"--for example, "have hope." This "concept-asobject" metaphor, which underlies the described analysis system, is more general than the metaphor themes of Lakoff and Johnson (1980), such as "IDEAS ARE FOOD." In fact, its generality approaches the level at which syntax implements the metaphor (e.g., nouns represent actions).

Explicit predications expressed in simple abstract language (e.g., "have hope") are already richer than the attributive form in that they introduce another object into the conceptual structure. Making a noun out of an abstract concept not only facilitates talking about mental concepts, perception and abilities, but also sets up the image for metaphor in terms of implicit effects by allowing correspondence with a spatial image containing objects other than an actor or experiencer. As an example, consider how one might generate the metaphor "The news torpedoed his hope." If a person who suddenly stops hoping is reminded of an image in which his boat is torpedoed in battle, a noun is needed to take the place of the boat, and this noun informs the hearer what the topic is, namely, his hopeful state. The verb "torpedo" is then the verbal vehicle, while a syntactic direct object such as "hope" implicitly represents the boat. This is consistent with Miller's (1979) observation that conceptual elements of a comparison which are left out are nonetheless constrained. Thus "Root out your faults" could be expressed as "Eliminate your faults as you would root out weeds." Similar considerations are relevant to the analysis or generation of the nominal metaphor "The news was a torpedo."

Consistent with these observations, the Metaphor Analysis Program, with its built-in metaphoric representation scheme, "recognizes" mental and other nonphysical attributes as "alienated" concepts "located at" experiencers--for example, "hope AT (+ANIMATE) LOCATION." At the same time, by acknowledging the (verbal-attributive) conceptual category of such concepts, it can generate the verbal form "He stopped hoping." The program thus incorporates the recognition that the originator's process of object creation (i.e., recourse to the "concept-as-object" metaphor) provides a tool for conveying specific experiences to a recipient.

These considerations of the syntax and semantics of metaphoric extension suggest three levels at which linguistic expressions can be considered metaphoric, independent of the extent to which such usages may be assimilated into everyday language:

1. The level at which language in general is metaphoric because it is a symbolic representation and analyzes events into action and object categories (cf. Breal, 1900/1964, "Language is a translation of reality," p. 247). In this sense, even literal predications about physical objects, as well as ostensibly nonmetaphoric elements of linguistic or computer representations, are metaphoric. 
2. The level of abstract language as described above, based on manipulation of nonphysical concepts as objects. The literal interpretation of language which is metaphoric only in this sense (e.g., "His hope ended") is then equivalent to undoing nominalizations.

3. Metaphor in the conventional sense, whether frozen (in which the experiential aspect is no longer active) or novel. The "frozen" category includes certain elements of some computer representations, such as Schank's (1975) MBUILD (mentally build) or MTRANS (mentally transfer).

These levels are represented in order of increasing metaphoricity in Figure 5.

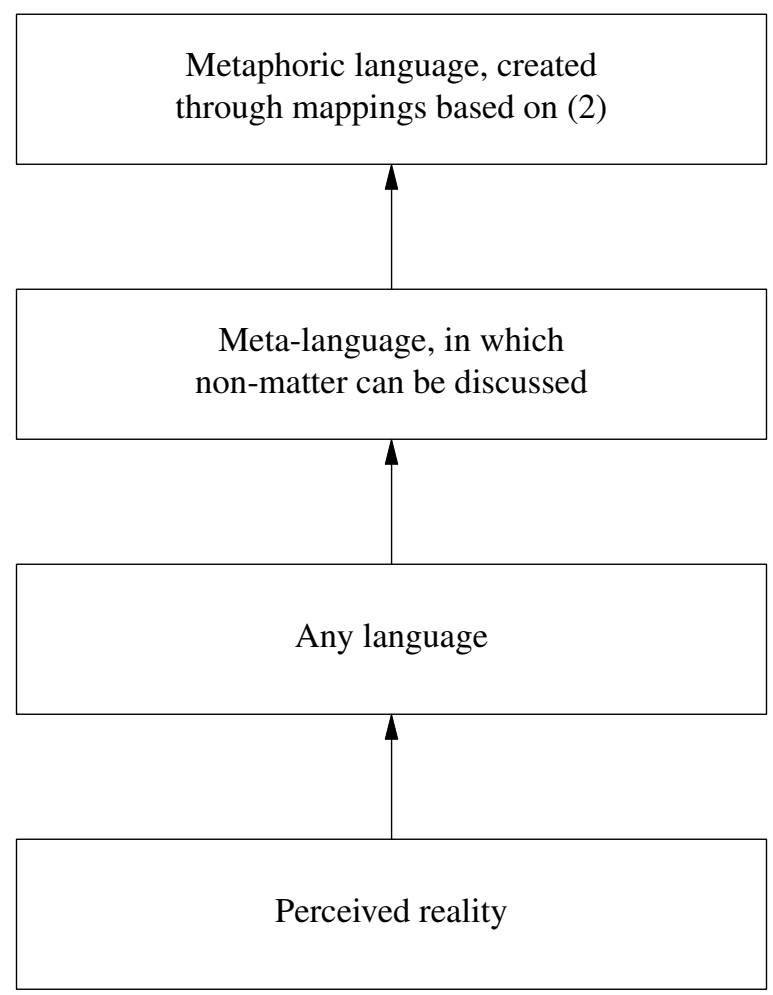

Figure 5. Levels of metaphoric language.

This scale of increasingly powerful representation depicts metaphor as language creation. In terms of Figure 5, the Metaphor Analysis Program has the capability of transforming language which is relatively creative, (i.e., metaphoric in the sense of Levels 2 or 3) into something more familiar. In retrieving explicit predications, it maps structures derived from input verbs into the premetaphoric structures of Level 2, which can then be mapped into denominalized and thus "more literal" paraphrases of Level 1. In the case of Level 3 metaphor, verbal decomposition allows the program to retrieve the affective responses and other abstracted implicit factors of the mediated experience.

It is creative linguistic devices such as the nominalization of abstract concepts and the metaphoric extension of being to having at Level 2 which allow the organization of the richer semantic and pragmatic aspects of a vehicle experience. The described system recognizes this phenomenon in producing, for an input metaphor, various syntactic paraphrases which include connotations of the vehicle experience. The analyses which generate such paraphrases thus help to clarify how abstract metaphor is particularly suited to conveying intentionally evoked experience. 


\section{CONCLUSION}

By isolating the affective and nonaffective common ground of a metaphor in terms of extensible components, the given analyses identify the similarity of the relations underlying the metaphoric and target expressions as called for by Searle (1979). The formalizations as implemented in a program, applied to metaphoric input, yield output "interpretations" that can be experimentally compared with human interpretations of the same input. The model therefore provides a specific means of testing theories on how metaphors work--or do not work.

Pending such testing, the preceding discussion suggests that computer analyses of metaphor could conceivably reveal what the originator wants to say and possibly why, along with typical effects on a recipient of the metaphor. Analyses might even describe how the originator arrived at a particular position or perception of the analogy. For instance, given the dynamic memory organizations of Schank $(1979,1985)$, an episode or concept which a natural language analysis program "recognizes" as a deviation with respect to the norm could be considered in Winston's (1978) terminology as "distinct with respect to its class." A reminder (through abstract representations) of this episode by a similar episode would then provide a basis for generating at least idiosyncratic metaphor.

On the other hand, an analysis cannot re-present all that could be conveyed as a result of the originator's intention--the experience which unites the recipient with the originator's perception, entertains, or manipulates. Of interdisciplinary concern, these diverging conclusions do not necessarily conflict, but rather point to the possibilities and limits of exploring two different dimensions of language understanding. 


\section{ACKNOWLEDGMENTS}

I am indebted to co-editor Robert Hoffman for his help in unmuddying the theoretical and discursive waters; to Jim Weiner for pointing to paths out of the forest; to Bob Russell for taking the roles of guinea pig, standard-bearer on behalf of the besieged reader, and supportive rock in the presence of crevasses in all three mental domains of the author; and to Yorick Wilks for ensuring that fewer stones were left unturned. In paraphrase, all had a positive effect on this article. I also express my appreciation to Helen Gigley for vacuuming up resources in various gold mines. Finally, I thank Maghi King and the Institute for Semantic and Cognitive Studies in Geneva for providing a plowed field in which some of these ideas could germinate. 


\section{REFERENCES}

Allen, J., \& Perrault, C. R. (1980). Analyzing intention in utterances. Artificial Intelligence, 15, 143-178.

Black, M. (1962). Models and Metaphors. Ithaca, NY: Cornell University Press.

Black, M. (1979). More about metaphor. In A. Ortony (Ed.), Metaphor and Thought (pp. 19-43). Cambridge, England: Cambridge University Press.

Breal, M. (1964). Semantics: Studies in the Science of Meaning. New York: Dover. (Original work published 1900)

Carbonell, J. (1980). Metaphor: A key to extensible semantic analysis. In Proceedings of the 18th Annual Meeting of the Association for Computational Linguistics (pp. 17-21).

Carbonell, J. (1982). Metaphor: An inescapable phenomenon in natural-language comprehension. In W. Lehnert \& M. Ringle (Eds.), Strategies for Natural Language Processing (pp. 415-434). Hillsdale, NJ: Lawrence Erlbaum Associates, Inc.

Carbonell, J., \& Minton, S. (1983). Metaphor and common-sense reasoning (Rep. No. CMU-CS-83-110). Pittsburgh: Carnegie-Mellon University.

Dreikurs, T. (1964). Children: The Challenge, New York: Hawthorn.

Dyer, M. ( 1982). Affect processing for narratives. In Proceedings of the National Conference on Artificial Intelligence (pp. 265-268).

Fass, D., \& Wilks, Y. (1983). Preference semantics, ill-formedness, and metaphor. American Journal of Computational Linguistics, 9, 178-187.

Gentner, D. (1975). Evidence for the psychological reality of semantic components: The verbs of possession. In D. Norman \& D. Rumelhart (Eds.), Explorations in Cognition (pp. 211-246). San Francisco: Freeman.

Gentner, D. (1980, September). Studies of metaphor and complex analogies: a structure-mapping theory. In R. Hoffman (Chair), Metaphor as Process. Symposium conducted at the annual meeting of the American Psychological Association, Montreal.

Gentner, D. (1982). Are scientific analogies metaphors? In D. Miall (Ed.), Metaphor: Problems and Perspectives (pp. 106-132). Brighton, England: Harvester.

Gibson, J. (1977). The theory of affordances. In R. Shaw and J. Bransford (Eds.), Perceiving, acting and knowing (pp. 67-82). Hillsdale, NJ: Lawrence Erlbaum Associates, Inc.

Hobbs, J. (1979). Metaphor, schemata and selective inferencing (Rep. No. 204). Menlo Park, CA: SRI.

Hobbs, J. (1981). Metaphor interpretation as selective inferencing. Proceedings of the 7th International Joint Conference on Artificial Intelligence, 1, 85-91.

Hoffman, R. (1985). Some implications of metaphor for philosophy and psychology of science. In R. Dirven \& W. Paprotte (Eds.), The ubiquity of metaphor. Amsterdam: John Benjamins.

Honeck, R., Voegtle, K., Dorfmueller, M., \& Hoffman, R. (1980). Proverbs, meaning and group structure. In 
R. Honeck and R. Hoffman (Eds.), Cognition and figurative language (pp. 127-161). Hillsdale, NJ: Lawrence Erlbaum Associates, Inc.

Indurkhya, B. (1985). A computational model of metaphor comprehension and analogical reasoning (Rep. No. 85/001). Boston: Boston University.

Janssens, Y. (1981, August 9). Une cathedrale de cristal en Californie. La Suisse, p. 27

Jastrow, R. (1947). Red giants and white dwarfs, New York: Harper and Row.

Johnson, M. (1982, August). The preconceptual basis of experiential metaphor. In A. Ortony (Chair), Metaphor: Topic-vehicle relations in comprehension. Symposium conducted at the annual meeting of the American Psychological Association, Washington, DC.

Johnson, M., \& Malgady, R. (1980). Toward a perceptual theory of metaphor comprehension. In R. Honeck and R. Hoffman (Eds.), Cognition and figurative language (pp. 259-282). Hillsdale, NJ: Lawrence Erlbaum Associates, Inc.

Kilpatrick, P. (1982). An A-frame model for metaphor. In Proceedings of the International Conference on Cybernetics and Society, (pp. 83-87).

King, S. (1982, February 16). AFL-CIO's Kirkland meets Bush, attacks 'Jonestown Economics.' The New York Times, p. 1.

Lakoff, G., \& Johnson, M. (1980). Metaphors we live by. Chicago: Chicago University Press.

MacKay, D. (1969). Information, mechanism and meaning. Cambridge, MA: M. I. T. Press.

Miller, G. (1979). Images and models, similes and metaphors. In A. Ortony (Ed.), Metaphor and Thought (pp. 202-250). Cambridge, England: Cambridge University Press.

Norman, D., \& Rumelhart, D. (Eds.) (1975). Explorations in cognition. San Francisco: Freeman.

Ortony, A. (1979a). Beyond literal similarity. Psychological Review, 86, 161-180.

Ortony, A. (1979b). The role of similarity in similes and metaphors. In A. Ortony (Ed.), Metaphor and thought (pp. 186-201). Cambridge, England: Cambridge University Press.

Osgood, C. (1980). The cognitive dynamics of synesthesia and metaphor. In R. Honeck \& R. Hoffman (Eds.), Cognition and figurative language (pp. 203-238). Hillsdale, NJ: Lawrence Erlbaum Associates, Inc.

Paivio, A. (1979). Psychological processes in the comprehension of metaphor. In A. Ortony (Ed.), Metaphor and thought (pp. 150-171). Cambridge, England: Cambridge University Press.

Paul, A. (1972). Metaphor and the bounds of expression. Philosophy and Rhetoric, 5, 143-158.

Perrault, C. R., \& Allen, J. (1980). A plan-based analysis of indirect speech acts. American Journal of Computational Linguistics, 6, 167-182.

Perrault, C. R., Allen, J., \& Cohen, P. (1978). Speech acts as a basis for understanding dialogue coherence. In Proceedings of the Second Conference on Theoretical Issues in Natural Language Processing (pp. 125-132). 
Pollio, H., Barlow, J., Fine, H., \& Pollio, M. (1977). Psychology and the poetics of growth: Figurative language in psychology, psychotherapy and education. Hillsdale, NJ: Lawrence Erlbaum Associates, Inc.

Richards, I. A. (1936). The Philosophy of rhetoric. London: Oxford University Press.

Rieger, C. (1975). Conceptual memory and inference. In R. Schank (Ed.), Conceptual Information Processing (pp. 157-288). Amsterdam: North Holland.

Russell, S. Weber (1975). Computer understanding of conceptually complex phrases. Dissertation Abstracts International, 36, 2355B-2356B. (University Microfilms No. 75-25, 600)

Russell, S. Weber (1976). Computer understanding of metaphorically used verbs. American Journal of Computational Linguistics, Microfiche 44.

Russell, S. Weber (1982). Formalizing factors in metaphorical extension. In Proceedings of the European Conference on Artificial Intelligence, 234-239.

Russell, S. Weber (1985). Conceptual analysis of partial metaphor [condensed revision of Russell, 1982]. In L. Steels \& J. Campbell (Eds.), Progress in Artificial Intelligence (pp. 193-201). Chichester, England: Ellis Horwood.

Salmans, S., DeFrank, T., Buresh, B., \& Hubbard, H. (1975, July 7). A Ford in high gear. Newsweek, p. 13.

Schank, R. (1972). Adverbs and belief (Report No. AIM-171). Stanford, CA: Stanford University.

Schank, R. (1975). Conceptual Information Processing. Amsterdam: North Holland.

Schank, R. (1985). Looking at learning. In L. Steels \& J. Campbell (Eds.), Progress in Artificial Intelligence (pp. 17-29).

Schank, R. (1979). Reminding and memory organization: An introduction to MOPS (Rep. No. 170). New Haven, CT: Yale University, Department of Computer Science.

Schank, R., \& Abelson, R. (1977). Scripts, plans, goals and understanding. Hillsdale, NJ: Lawrence Erlbaum Associates, Inc.

Searle, J. (1979). Metaphor: In A. Ortony (Ed.), Metaphor and thought (pp. 92-123). Cambridge, England: Cambridge University Press.

Sloman, A., \& Croucher, M. (1981). You don't need a soft skin to have a warm heart: Towards a computational analysis of motives and emotions (Rep. No. CSRP 004). Brighton, England: University of Sussex.

Smith, M., \& Montgomery, M. (1982). The semantics of winning and losing. Knoxville: University of Tennessee, Department of Psychology.

Turbayne, C. (1971). The myth of metaphor. Columbia: University of South Carolina Press.

Verbrugge, R. (1980). Transformations in knowing: A realist view of metaphor. In R. Honeck and R. Hoffman (Eds.), Cognition and figurative language (pp. 87-125). Hillsdale, NJ: Lawrence Erlbaum Associates, Inc.

Vinocur, J. (1982, March 28). In Bonn, the coalition's decline accelerates. The New York Times, "The Week in 
Review," p. 2.

Weiner, E. J. (1984). A knowledge representation approach to understanding metaphors. Computational Linguistics, 10, 1-14.

Wilks, Y. (1977a). Good and bad arguments about semantic primitives (Rep. No. 42). Colchester, England: University of Essex, Department of Artificial Intelligence.

Wilks, Y. (1977b). Knowledge structures and language boundaries. Proceedings of the 5th International Joint Conference on Artificial Intelligence, 1, 151-157.

Wilks, Y. (1978). Making preferences more active. Artificial Intelligence, 11, 197-223.

Winograd, T. (1983). Language as a cognitive process. Menlo Park, CA: Addison-Wesley.

Winston, P. (1978). Learning by creating and justifying transfer frames. Artificial Intelligence, 10, 147-172. 


\section{APPENDIX}

Representation Components for Verbal Concepts

\section{EXPLICIT FACTORS}

State structures

"States," the basis of every verbal representation, predicate the existence of, attributes of, or relations between nominalized "concepts" filling one of two "roles," in the sense of case theory. Concepts are of the following three types:

LOCATIONs: concepts which for non-PHYSICAL domains are animate and therefore "experiencers."

OBJECTs: "domain-specific concepts" which for non-PHYSICAL domains are dependent on or "possessed by" experiencers, i.e. "idea." In PHYSICAL domains, animate concepts may be domain-specific OBJECTs in their capacity as physical objects, e.g. "John."

ATTRIBUTES: quantitative,

evaluative (POSITIVE/NEGATIVE), or

qualitative

abstract attributes dependent on level-specific OBJECTS (i.e., "be high (have great height), be good (have value), be red (have color red)"

The STATE-TYPE (underlying condition or result) is then specified alternatively as:

(1) (existential) OBJECT BE or OBJECT <ACT>

Example:

"exist, make, pulverize" OBJECT BE

"live, start up, kill" OBJECT FUNCTION

(2) (attributive) OBJECT BE <ATTRIBUTE $>$ : VALUE>

Example:

"grow" OBJECT BE AMOUNT: MORE HIGH

"deteriorate" OBJECT BE EVALUATION: MORE NEGATIVE

(3) (relational) OBJECT (BE) AT <LOCATION>

(AT here expresses general identity of or association of OBJECT and LOCATION)

Example:

"wear, paint, disenfranchise" OBJECT AT LOCATION 
Roles

ROLE, for a verb definition that includes an underlying relational state, specifies whether the nominal described by the state is the "dominant" (or "possessing") concept of the state (LOCATION role) or the "subordinate" (or "possessed") concept (OBJECT role). For an attributive underlying state, the ROLE specification is OBJECT. Examples are:

LOCATION "drop, lose"

OBJECT "leap to, belong to, brighten, live"

Other components (for binary components, examples are for positive values)

TRANS specifies change of state, optionally focused alternatively on:

entering: TRANS: ENTER-STATE "appear, brighten"

leaving: $\quad$ TRANS: LEAVE-STATE "die, deprive, shed"

passing through: TRANS: THRU-STATE "plow through"

AGENT (causative) <+,-> "paint, pulverize, disenfranchise"

SYMMETRIC (shared action or state) <+,-> "drift apart"

TRY (attempted STATE) $\langle+,->\quad$ "offer, aim for"

HYPOTHETICAL (potential STATE) <+,-> "close, be susceptible, immunize"

\section{IMPLICIT FACTORS}

Character of the verb

$\begin{array}{ll}\text { SPEED < HIGH, LOW> } & \text { "race," "leap" vs. "crawl" } \\ \text { REPEATED <+,-> } & \text { "shuttle" } \\ \text { CONTINUOUS <+,-> } & \text { "glide" vs. "lurch" }\end{array}$

Character of the actor (AGENT or LOCATION)

VOLUNTARY (intentional) <+,-> "relinquish" vs. "lose"

Response of a participant or recipient

EVALUATION <POSITIVE, NEGATIVE> " "be breezy" vs. "be drafty"

FORCE (intensity, effort) < HIGH, LOW> "plow through" vs. "glide through"

(Cf. Osgood's (1980) "evaluative" and "potency" factors.)

Affective factors < HIGH, LOW>, e.g. FEAR: HIGH "guillotine" 


\section{Contents}

The Question of Communicated Content .............................................................................. 3

Experiential Metaphor as a Tool of Intention ............................................................... 4

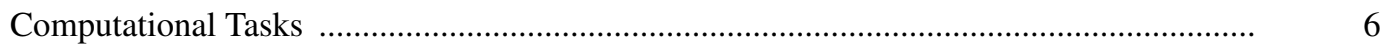

Artificial Intelligence Research on Metaphor ………….................................................... 7

Framework of a Metaphor Analysis Model ...................................................................... 16

Representing Vehicle Concepts ............................................................................. 18

Identifying Salient Properties of Nominals ....................................................................... 22

Experience and Computer Representation ..................................................................... 27

Metaphor Representation and Language ………........................................................ 28

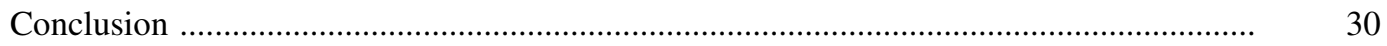

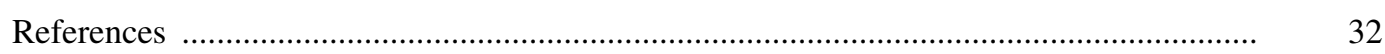

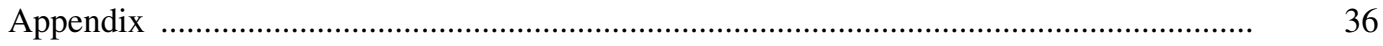

